\title{
Early DNA methylation changes in children developing beta cell autoimmunity at a young age
}

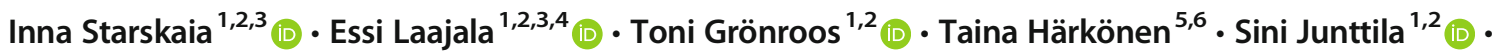 \\ Roosa Kattelus $^{1,2} \cdot$ Henna Kallionpää ${ }^{1}$ (D) $\cdot$ Asta Laiho ${ }^{1,2}$ (D) Veronika Suni ${ }^{1}$ (D) Vallo Tillmann $^{7,8}$ (D) $\cdot$ Riikka Lund $^{1}$ (D) . \\ Laura L. Elo ${ }^{1,2,9}$ (1) $\cdot$ Harri Lähdesmäki ${ }^{4}$ (]) Mikael Knip $^{5,6,10}$ (D) Ubaid Ullah Kalim ${ }^{1,2}$ (D) $\cdot$ Riitta Lahesmaa $^{1,2,9}$ (D)
}

Received: 11 July 2021 / Accepted: 10 November 2021 / Published online: 10 February 2022

(C) The Author(s) 2022

\begin{abstract}
Aims/hypothesis Type 1 diabetes is a chronic autoimmune disease of complex aetiology, including a potential role for epigenetic regulation. Previous epigenomic studies focused mainly on clinically diagnosed individuals. The aim of the study was to assess early DNA methylation changes associated with type 1 diabetes already before the diagnosis or even before the appearance of autoantibodies.

Methods Reduced representation bisulphite sequencing (RRBS) was applied to study DNA methylation in purified $\mathrm{CD} 4^{+} \mathrm{T}$ cell, $\mathrm{CD}^{+} \mathrm{T}$ cell and $\mathrm{CD} 4^{-} \mathrm{CD} 8^{-}$cell fractions of 226 peripheral blood mononuclear cell samples longitudinally collected from seven type 1 diabetes-specific autoantibody-positive individuals and control individuals matched for age, sex, HLA risk and place of birth. We also explored correlations between DNA methylation and gene expression using RNA sequencing data from the same samples. Technical validation of RRBS results was performed using pyrosequencing.

Results We identified 79, 56 and 45 differentially methylated regions in $\mathrm{CD} 4^{+} \mathrm{T}$ cells, $\mathrm{CD} 8^{+} \mathrm{T}$ cells and $\mathrm{CD} 4^{-} \mathrm{CD} 8^{-}$cell fractions, respectively, between type 1 diabetes-specific autoantibody-positive individuals and control participants. The analysis of pre-seroconversion samples identified DNA methylation signatures at the very early stage of disease, including differential methylation at the promoter of IRF5 in $\mathrm{CD}^{+} \mathrm{T}$ cells. Further, we validated RRBS results using pyrosequencing at the following CpG sites: chr19:18118304 in the promoter of ARRDC2; chr21:47307815 in the intron of PCBP3; and chr14:81128398 in the intergenic region near TRAF3 in $\mathrm{CD} 4^{+} \mathrm{T}$ cells.

Conclusions/interpretation These preliminary results provide novel insights into cell type-specific differential epigenetic regulation of genes, which may contribute to type 1 diabetes pathogenesis at the very early stage of disease development. Should these findings be validated, they may serve as a potential signature useful for disease prediction and management.
\end{abstract}

Keywords DNA methylation $\cdot$ Epigenetics $\cdot$ T cells $\cdot$ Type 1 diabetes

Riitta Lahesmaa and Ubaid Ullah Kalim share last authorship.

Ubaid Ullah Kalim ubaid.ullah@utu.fi

Riitta Lahesmaa rilahes@utu.fi

1 Turku Bioscience Centre, University of Turku and Åbo Akademi University, Turku, Finland

2 InFLAMES Research Flagship Center, University of Turku, Turku, Finland

3 Turku Doctoral Programme of Molecular Medicine, University of Turku, Turku, Finland

4 Department of Computer Science, Aalto University, Espoo, Finland
5 Pediatric Research Center, Children's Hospital, University of Helsinki, and Helsinki University Hospital, Helsinki, Finland

6 Research Program for Clinical and Molecular Metabolism, Faculty of Medicine, University of Helsinki, Helsinki, Finland

7 Children's Clinic of Tartu University Hospital, Tartu, Estonia

8 Institute of Clinical Medicine, University of Tartu, Tartu, Estonia

9 Institute of Biomedicine, University of Turku, Turku, Finland

10 Tampere Center for Child Health Research, Tampere University Hospital, Tampere, Finland 


\section{Research in context}

\section{What is already known about this subject?}

- Changes in DNA methylation in blood cells have been reported in children with overt type 1 diabetes

- Array-based methods have revealed DNA methylation changes in blood cells of pre-disease individuals

\section{What is the key question?}

- Can we identify DNA methylation changes associated with type 1 diabetes already before appearance of autoantibodies and clinical diagnosis in cell subsets of peripheral blood mononuclear cells using an unbiased genome-wide approach?

\section{What are the new findings?}

- We identified numerous significant DNA methylation changes in $\mathrm{CD}^{+} \mathrm{T}$ cell, $\mathrm{CD}^{+} \mathrm{T}$ cell and $\mathrm{CD} 4^{-} \mathrm{CD} 8^{-}$cell fractions of peripheral blood mononuclear cells between pre-disease individuals and their matched control participants

- We identified DNA methylation changes in genes involved in immune response pathways, including IL32, TRAF3 and IRF5

- We found epigenetic variation in the genes with fewer known functions in type 1 diabetes pathogenesis, such as $A R R D C 2, D G K Q$ and PCBP3

\section{How might this impact on clinical practice in the foreseeable future?}

- Early epigenetic changes associated with type 1 diabetes identified in this study may be useful for disease prediction and management

\begin{tabular}{|c|c|}
\hline \multicolumn{2}{|c|}{ Abbreviations } \\
\hline \multicolumn{2}{|c|}{ cis-eQTM cis } \\
\hline & trait methylation \\
\hline DAG & Diacylglycerol \\
\hline DAISY & The Diabetes Autoimmunity \\
\hline & Study in the Young \\
\hline DMC & Differentially methylated $\mathrm{CpG}$ site \\
\hline DMR & Differentially methylated region \\
\hline eQTM & Expression quantitative trait methylation \\
\hline FDR & False discovery rate-corrected $p$ value \\
\hline FUT & Fucosyltransferase \\
\hline GADA & $\begin{array}{l}\text { Autoantibodies targeting } \\
\text { glutamic acid decarboxylase }\end{array}$ \\
\hline $\mathrm{GO}$ & Gene Ontology \\
\hline IA-2A & Autoantibodies targeting islet antigen-2 \\
\hline IAA & Autoantibodies targeting insulin \\
\hline IBD & Inflammatory bowel disease \\
\hline PBMC & Peripheral blood mononuclear cell \\
\hline RA & Rheumatoid arthritis \\
\hline RNA-seq & RNA sequencing \\
\hline RRBS & $\begin{array}{l}\text { Reduced representation bisulphite } \\
\text { sequencing }\end{array}$ \\
\hline RU & Relative units \\
\hline TCR & $\mathrm{T}$ cell receptor \\
\hline TSS & Transcription start site \\
\hline $\mathrm{ZnT} 8 \mathrm{~A}$ & Autoantibodies targeting zinc transporter -8 \\
\hline
\end{tabular}

\section{Introduction}

Type 1 diabetes is a complex autoimmune disease with a strong genetic component. Genome-wide association studies (GWAS) have identified more than 60 genetic loci associated with the risk of type 1 diabetes [1-3]. However, genetic variation alone cannot explain the conspicuous rise in the disease incidence during the past decades [4]. Several environmental factors, including viral infections, diet, toxins and other determinants, have been implicated [5].

Environmental exposures may result in epigenetic modifications of DNA, chromatin and histone proteins that change the level of gene expression. The importance of epigenetic gene regulation in complex disease phenotypes has been highlighted for several autoimmune disorders, such as rheumatoid arthritis (RA) and inflammatory bowel disease (IBD) [6, 7].

Fig. 1 Study design and analysis workflow schematics. (a) Study design. Each case individual is visualised as a red line above the corresponding control individual, visualised as a black line. The sample collection time points are marked as triangles. Diagnosis of type 1 diabetes and seroconversion are marked as blue and red asterisks, respectively. (b) The schematic shows the outline of the RRBS data analysis workflow. Both (a) and (b) were created with BioRender. M-biases, biased average methylation level at $5^{\prime}$ or $3^{\prime}$ of the reads; $\mathrm{PC} 1$, principal component 1 ; PC2, principal component 2; PCA, principal component analysis 
a

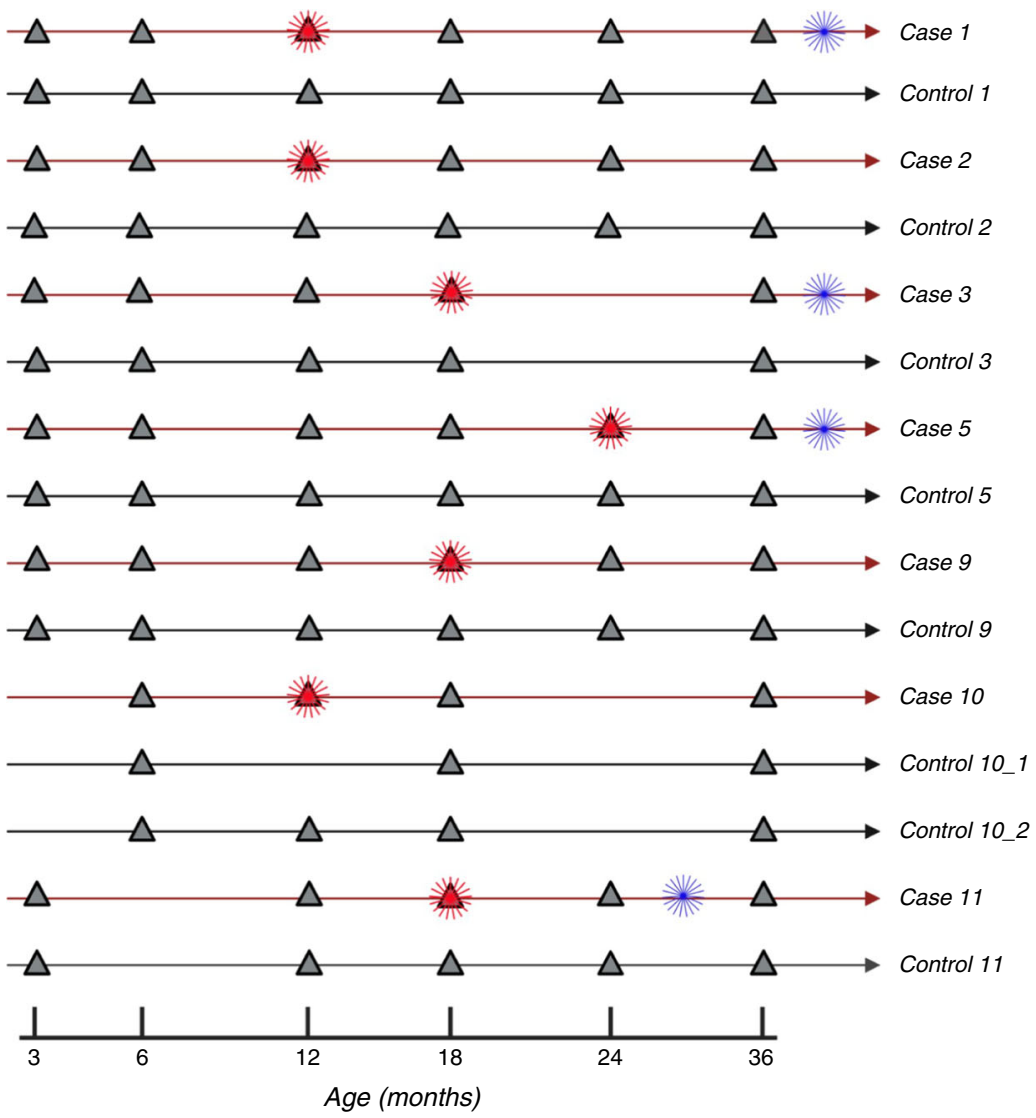

b

1. Preprocessing

TrimGalore, fastQC and Bismark-alignment of paired-end RRBS reads

\section{Extraction of methylation counts} Bismark methylation extractor, removed M-biases, merged information from both strands

\section{SNP removal} BS-SNPer for merged bam files

\section{Coverage filtering}

Removed CpGs with coverage >99.9th percentile Merged technical replicates

Required minimum coverage 10 in at least 2 matching time points in at least 5 (out of 7 ) case-control pairs

\section{Differential methylation analysis}

PQLseq + spatial combination to DMRs for (1) all samples and (2) the samples collected before seroconversion

Covariates: PC1, PC2, class, age, pair, individual

\section{Interpretation}

Annotation to genomic parts and nearest genes Observed methylation-expression correlations Known eQTM effects (BIOS QTL database)

GeneHancer database

Pathway enrichment analysis

\section{Validation of selected targets by bisulphite pyrosequencing}


a
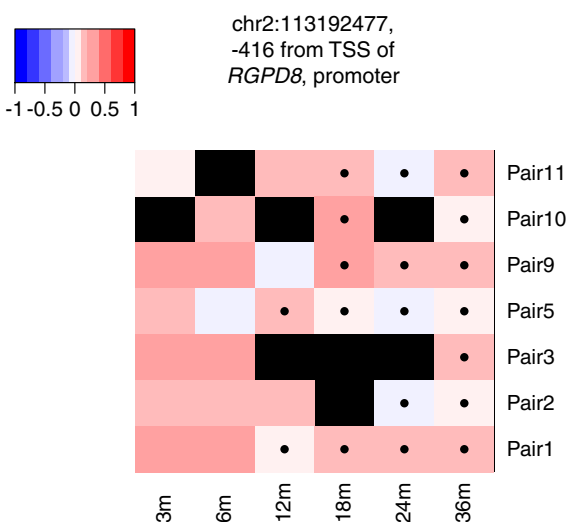

C
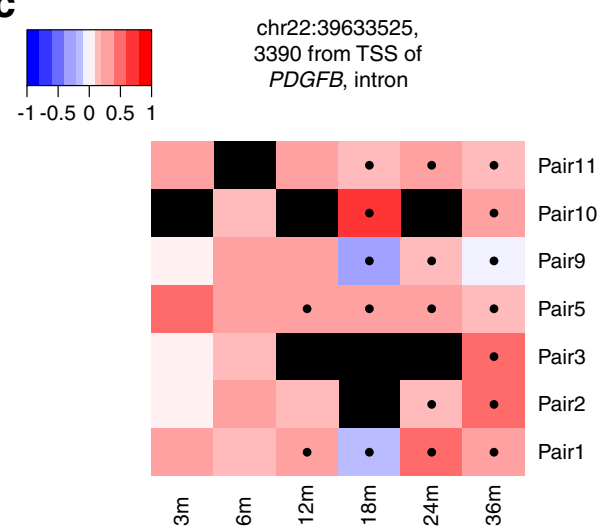

e
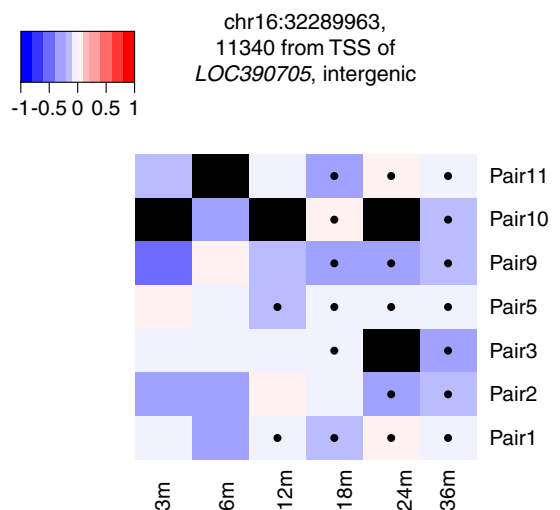

g
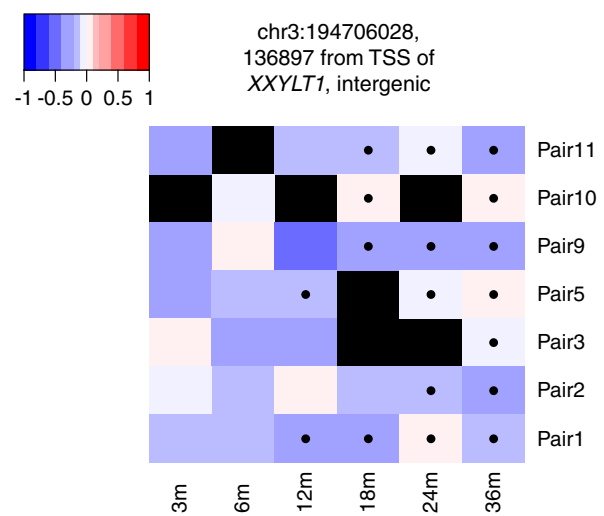

b
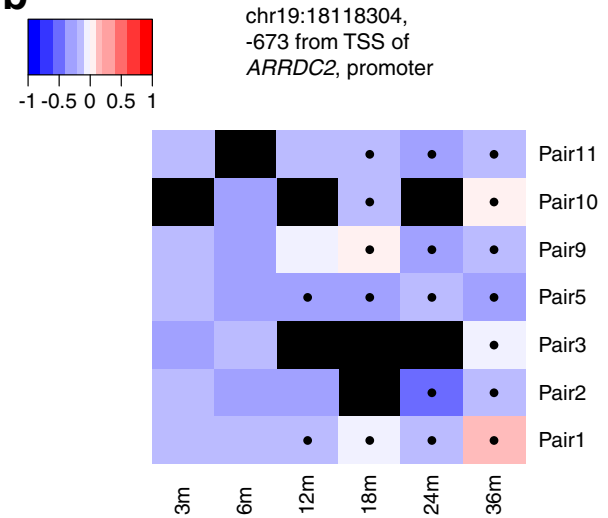

d
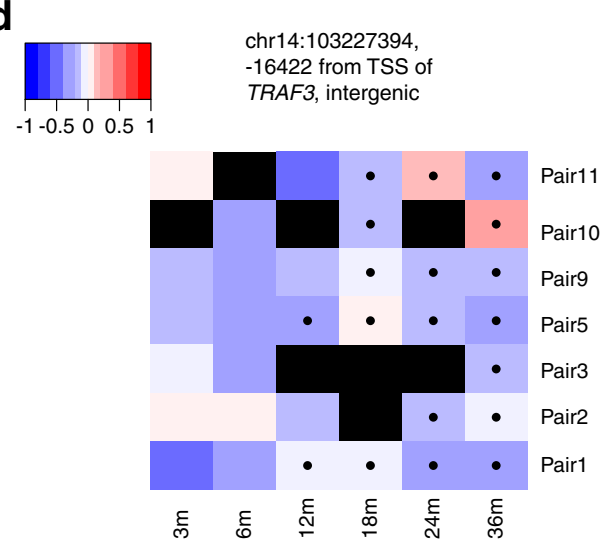

f
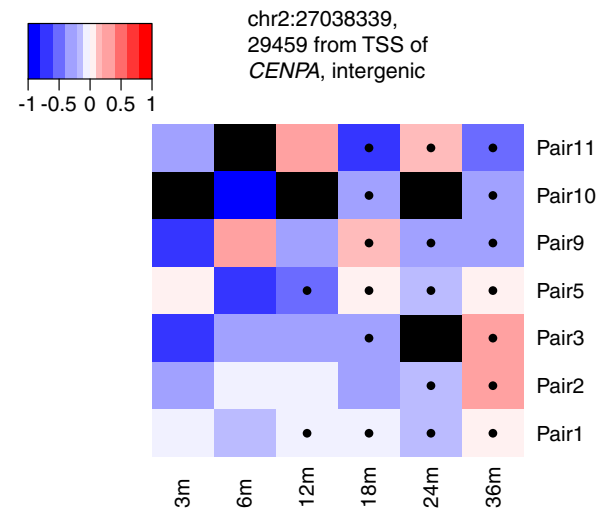

h
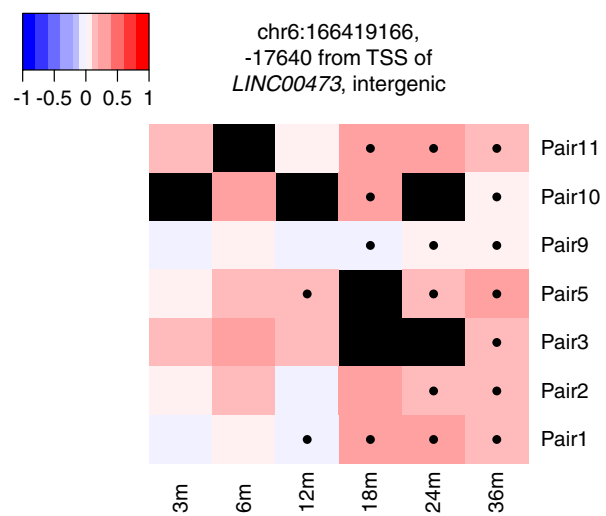
4 Fig. 2 DMCs. Methylation profiles of top-ranked DMCs between cases and controls identified in $\mathrm{CD}^{+} \mathrm{T}$ cells $(\mathbf{a}-\mathbf{d}), \mathrm{CD}^{+} \mathrm{T}$ cells $(\mathbf{e}, \mathbf{f})$ and $\mathrm{CD} 4^{-} \mathrm{CD} 8^{-}$fractions $(\mathbf{g}, \mathbf{h})$. The plots are coloured according to the pairwise methylation difference, as specified in the colour key. Blue and red indicate hypo- and hypermethylation of the $\mathrm{CpG}$ site in cases, compared with controls, respectively. Black represents missing values. The pairs of individuals are not in any particular order. A black dot in the boxes indicates a sample collected after seroconversion. m, months

DNA methylation is one of the most well-studied and key epigenetic modifications. It represents the addition of a methyl group to cytosine usually at the $\mathrm{CpG}$ dinucleotide and is typically associated with gene expression silencing [8].

A few studies identified a link between DNA methylation in circulating immune cells and type 1 diabetes [9-13]. However, most of those studies focused on individuals who had already developed clinical type 1 diabetes. A recent study examined DNA methylation changes in peripheral blood samples longitudinally collected before the diagnosis of type 1 diabetes from children enrolled in the prospective Diabetes Autoimmunity Study in the Young (DAISY) cohort [14]. However, the study was limited by the use of a $450 \mathrm{~K}$ array for methylation profiling that restricts the analysis to approximately 450,000 targeted CpG sites.

The detection of type 1 diabetes-associated autoantibodies targeting insulin (IAA), glutamic acid decarboxylase (GADA), tyrosine phosphatase-like protein (islet antigen-2, IA-2A) and zinc transporter-8 (ZnT8A) is currently the primary method to predict the development of type 1 diabetes. Children who develop multiple autoantibodies are very likely to progress to type 1 diabetes [15]. However, the appearance of autoantibodies is an indication of an already ongoing autoimmune reaction. Therefore, discovery of methylation changes at the early stages of disease onset, before seroconversion, could provide new insights into molecular mechanisms leading to type 1 diabetes.

The aim of this study was to assess early DNA methylation changes associated with type 1 diabetes in longitudinally collected samples from children who later developed islet autoimmunity at a young age. We used the reduced representation bisulphite sequencing (RRBS) approach instead of array-based methods to achieve broader coverage including sites that are not included in the arrays. Further, we purified the $\mathrm{CD}^{+} \mathrm{T}$ cell, $\mathrm{CD}^{+} \mathrm{T}$ cell and $\mathrm{CD} 4^{-} \mathrm{CD} 8^{-}$cell fractions of peripheral blood mononuclear cells (PBMCs) to determine cell type-specific methylation differences that have not been reported earlier. Besides identifying type 1 diabetes-associated DNA methylation changes, we investigated correlations between DNA methylation and gene expression, exploiting our earlier RNA sequencing (RNA-seq) study of the same samples [16]. The identification of early DNA methylation changes associated with type 1 diabetes will provide novel insights into the pathogenesis of the disease, and may serve as a potential signature for disease prediction and management.

\section{Methods}

Study cohort The cohort analysed here using RRBS is described in an earlier report on transcriptomics analysis of the same individuals [16]. DNA samples were longitudinally collected from seven case-control pairs of the Pathogenesis of Type 1 Diabetes - Testing the Hygiene Hypothesis (DIABIMMUNE) cohort (Fig. 1a, electronic supplementary material [ESM] Table 1). In total, we analysed 226 samples: 73,77 and 76 for $\mathrm{CD}^{+} \mathrm{T}$ cells, $\mathrm{CD}^{+} \mathrm{T}$ cells and $\mathrm{CD}^{-} \mathrm{CD}^{-}$cell fractions, respectively. The study protocols were approved by the ethics committees of the participating hospitals, and the parents gave written informed consent. HLA genotyping was described earlier [16]. Autoantibodies IAA, GADA, IA-2A and ZnT8A were measured from serum with specific radiobinding assays. The cutoff values were based on the 99th percentiles in children without diabetes, which were 2.80 relative units (RU) for IAA, 5.36 RU for GADA, 0.78 RU for IA-2A and 0.61 RU for ZnT8A. A sample was considered seropositive when any of the autoantibodies exceeded the threshold. The case individuals became positive for at least two type 1 diabetes-specific autoantibodies at the age of 1-2 years, whereas the control individuals remained autoantibody-negative throughout the follow-up period. The case-control pairs were matched by sex, place of birth, age and HLA risk class. The age was matched \pm 2 months except for the 36 months samples, where the samples were collected within 4 months. The HLA risk classes were defined as described earlier [17]. A detailed description of the study participants and their antibody measurements is presented in ESM Table 2.

Sample fractionation and DNA extraction PBMC sample collection, fractionation and viability of cells were as described earlier [16]. DNA was extracted from $\mathrm{CD}^{+} \mathrm{T}$ cells, $\mathrm{CD} 8^{+} \mathrm{T}$ cells and $\mathrm{CD} 4^{-} \mathrm{CD} 8^{-}$cell fractions with Qiagen's AllPrep Universal kit (Qiagen, Hilden, Germany, cat. No. 80224), according to the AllPrep DNA/RNA/miRNA Universal Handbook, 09/2012.

RRBS library preparation The library preparation from 100 ng of genomic DNA was carried out according to a protocol adapted from a gel-free multiplexed RRBS method [18]. Subsequent steps were performed as described earlier [19].

HiSeq 2500 sequencing The samples were normalised and pooled for the automated cluster preparation with an Illumina cBot station (Illumina, San Diego, CA, USA). $\mathrm{CD}^{+}{ }^{+}$cell libraries were run on eight lanes, 8-9 samples per lane. The $\mathrm{CD} 8^{+} \mathrm{T}$ cell libraries and $\mathrm{CD} 4^{-} \mathrm{CD} 8^{-}$cell fraction libraries were allocated to four pools, including 18-20 samples per pool. Each pool was run on three lanes. The samples were sequenced with an Illumina HiSeq 2500 instrument (Illumina) and TruSeq v3 sequencing chemistry (Illumina). Paired-end sequencing with 
$2 \times 100$-bp read length was used with a 6-bp index run. Technical quality of the HiSeq 2500 run was good, and the cluster amount was as expected. More than $76 \%$ of all bases above Illumina quality score Q30 was required. The sequencing runs of 37 samples were repeated due to low raw read counts (less than 30 million reads per sample). The median yield of the other samples was 47 million reads ( $\operatorname{read} 1+\operatorname{read} 2)$.

RRBS data analysis RRBS data analysis was performed as we described previously [20]. The data analysis workflow is summarised in Fig. 1b. More detailed description is also provided in the ESM Methods. Most of the data analysis was done with $\mathrm{R}$ versions 3.6.1 and 4.0.4 [21]. The heatmaps in Fig. 2 were produced with the R package hamlet [22]. Annotation of differentially methylated $\mathrm{CpG}$ sites (DMCs) to genomic regions was carried out through $\mathrm{R}$ package genomation version 1.16.0 [23] using Genome Reference Consortium Human Build 37 (GRCh37/hg19).

Expression quantitative trait methylation analysis A list of human whole blood cis-expression quantitative trait methylation (cis-eQTM, false discovery rate-corrected $p$ value $[\mathrm{FDR}]<0.1)$ effects was downloaded from the BIOS QTL database [24] (accessed 1 April 2020), which is based on 3841 Dutch peripheral blood samples.
Methylation-expression correlation analysis We utilised our published RNA-seq data from the same samples to calculate methylation-expression correlations. Spearman correlations across all samples within each cell fraction were calculated between each DMC and all genes with transcription start sites (TSSs) within a window of $250 \mathrm{~kb}$ in both directions from the CpG site's genomic location. The Ensembl identifiers and gene names are from Ensembl versions 70 [25] and 75 [26].

Pathway enrichment analysis Gene Ontology (GO) terms were used in the pathway enrichment analysis. Only DMCs with adjusted $p$ value (Benjamini-Hochberg-corrected $p$ value) $<0.1$ and their corresponding nearest and correlating genes were used for the analysis. Pathways were considered to be significantly enriched at FDR $<0.05$ (Fisher's exact test).

Pyrosequencing PyroMark assay design 2.0 software (Qiagen) was used to design the assays. Target-specific primers designed with the software include a primer pair with site-specific biotinylation for target amplification and a pyrosequencing primer. Sample preparations started with $200 \mathrm{ng}$ of DNA from three selected case-control pairs. Samples were first sodium bisulphite-treated with EZ DNA Methylation-Gold Kit (Zymo Research, Irvine, CA, USA, cat. No. D5006). Selected targets were then amplified by PyroMark PCR Kit (Qiagen, cat. No.

Table 1 Top-ranked DMCs at FDR $<0.0001$ identified between cases and controls in all longitudinal samples

\begin{tabular}{|c|c|c|c|c|c|c|}
\hline DMC (hg19) & Fraction & Methylation difference & $p$ value & FDR, $<0.0001$ & Nearest gene & Genomic region \\
\hline chr2:113192477 & $\mathrm{CD}^{+}{ }^{+}$ & 0.130 & $8.45 \times 10^{-13}$ & $1.25 \times 10^{-7}$ & $R G P D 8$ & Promoter \\
\hline chr11:42897003 & $\mathrm{CD}^{+}{ }^{+}$ & 0.456 & $1.42 \times 10^{-12}$ & $1.40 \times 10^{-7}$ & HNRNPKP3 & Intergenic \\
\hline chr7:22861070 & $\mathrm{CD}^{+}{ }^{+}$ & -0.160 & $2.61 \times 10^{-12}$ & $1.93 \times 10^{-7}$ & TOMM7 & Intron \\
\hline chr1:44878291 & $\mathrm{CD}^{+}$ & -0.104 & $4.46 \times 10^{-12}$ & $2.64 \times 10^{-7}$ & $R N F 220$ & Exon \\
\hline chr11:118842572 & $\mathrm{CD}^{+}{ }^{+}$ & 0.101 & $1.25 \times 10^{-10}$ & $3.71 \times 10^{-6}$ & FOXRI & Promoter \\
\hline chr14:103227394 & $\mathrm{CD}^{+}{ }^{+}$ & -0.150 & $5.86 \times 10^{-10}$ & $1.24 \times 10^{-5}$ & $T R A F 3$ & Intergenic \\
\hline chr6:121069653 & $\mathrm{CD} 4^{+}$ & -0.124 & $6.88 \times 10^{-10}$ & $1.34 \times 10^{-5}$ & C6orf170 & Intergenic \\
\hline chr9:137674085 & $\mathrm{CD} 4^{+}$ & -0.113 & $7.25 \times 10^{-10}$ & $1.34 \times 10^{-5}$ & MIR3689C & Intron \\
\hline chr19:18118304 & $\mathrm{CD} 4^{+}$ & -0.174 & $1.11 \times 10^{-9}$ & $1.94 \times 10^{-5}$ & $A R R D C 2$ & Promoter \\
\hline chr22:39633525 & $\mathrm{CD} 4^{+}$ & 0.189 & $1.77 \times 10^{-9}$ & $2.61 \times 10^{-5}$ & $P D G F B$ & Intron \\
\hline chr16:32289963 & $\mathrm{CD} 8^{+}$ & -0.130 & $5.21 \times 10^{-11}$ & $1.27 \times 10^{-5}$ & LOC390705 & Intergenic \\
\hline chr2:27038339 & $\mathrm{CD} 8^{+}$ & -0.186 & $2.78 \times 10^{-10}$ & $4.31 \times 10^{-5}$ & CENPA & Intergenic \\
\hline chr9:79557441 & $\mathrm{CD}^{+}$ & 0.154 & $5.37 \times 10^{-10}$ & $7.04 \times 10^{-5}$ & PRUNE2 & Intergenic \\
\hline chr14:45343058 & $\mathrm{CD}^{+}$ & -0.207 & $8.55 \times 10^{-10}$ & $9.11 \times 10^{-5}$ & C14orf 28 & Intergenic \\
\hline chr18:54333583 & $\mathrm{CD}^{-} \mathrm{CD}^{-}$ & 0.131 & $1.26 \times 10^{-17}$ & $7.62 \times 10^{-12}$ & $W D R 7$ & Intron \\
\hline chr14:57523325 & $\mathrm{CD}^{-} \mathrm{CD}^{-}$ & -0.299 & $5.17 \times 10^{-13}$ & $1.25 \times 10^{-7}$ & EXOC5 & Intergenic \\
\hline chr3:194706028 & $\mathrm{CD} 4^{-} \mathrm{CD} 8^{-}$ & -0.132 & $1.24 \times 10^{-12}$ & $2.51 \times 10^{-7}$ & $X X Y L T 1$ & Intergenic \\
\hline chr5:173991159 & $\mathrm{CD} 4^{-} \mathrm{CD} 8^{-}$ & 0.143 & $7.59 \times 10^{-12}$ & $1.32 \times 10^{-6}$ & $M S X 2$ & Intergenic \\
\hline chr19:38346420 & $\mathrm{CD} 4^{-} \mathrm{CD} 8^{-}$ & 0.115 & $1.14 \times 10^{-11}$ & $1.72 \times 10^{-6}$ & LOC100631378 & Promoter \\
\hline chr3:194705954 & $\mathrm{CD}^{-} \mathrm{CD}^{-}$ & -0.138 & $3.75 \times 10^{-11}$ & $5.06 \times 10^{-6}$ & XXYLT1 & Intergenic \\
\hline chr6:166419166 & $\mathrm{CD}^{-} \mathrm{CD}^{-}$ & 0.104 & $5.30 \times 10^{-11}$ & $6.44 \times 10^{-6}$ & LINC00473 & Intergenic \\
\hline chr11:134709660 & $\mathrm{CD} 4^{-} \mathrm{CD} 8^{-}$ & 0.215 & $2.73 \times 10^{-10}$ & $2.55 \times 10^{-5}$ & AK125040 & Intergenic \\
\hline
\end{tabular}


Fig. 3 DMRs. (a) Venn diagrams of the numbers of DMRs detected in different cell fractions. A DMR is considered to be found in two cell fractions if at least one DMC within the DMR is found in both cell fractions. Positive methylation difference means the DMR was hypermethylated in cases, compared with controls; negative means hypomethylated in cases, compared with controls. The figures were created with BioRender. (b) Distribution of DMRs in genomic regions in $\mathrm{CD}^{+} \mathrm{T}$ cells, $\mathrm{CD} 8^{+} \mathrm{T}$ cells and $\mathrm{CD} 4^{-} \mathrm{CD} 8^{-}$cell fractions a

Positive methylation difference (case-control) Negative methylation difference (case-control)
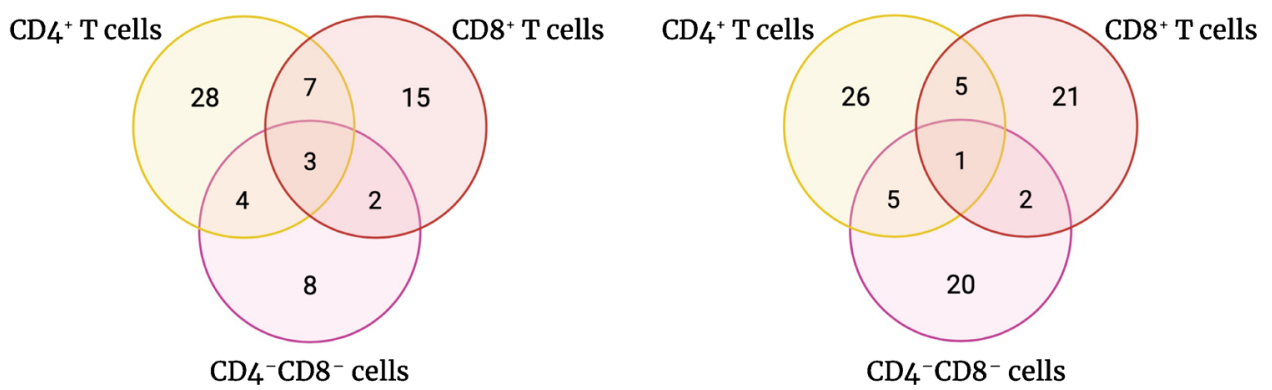

b

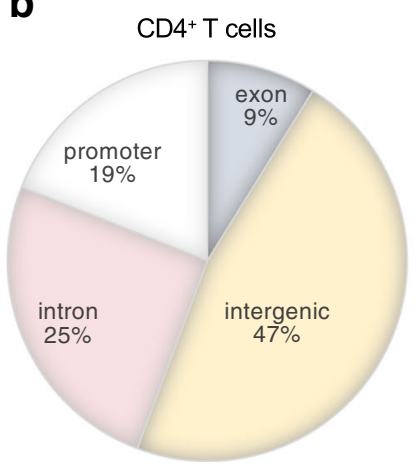

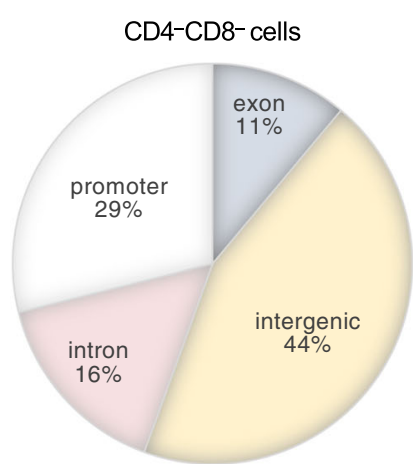

978703). A biotin-labelled template strand was then used for the pyrosequencing reaction with a specific primer using PyroMark Q24 system (Qiagen) with PyroMark Q24 Advanced CpG Reagents (Qiagen, cat. No. 970922).

\section{Results}

RRBS analysis of different cellular fractions identified methylation differences in children at risk for type 1 diabetes When including all the longitudinal samples into the differential methylation analysis model, we discovered 225, 114 and 87 DMCs in the $\mathrm{CD}^{+} \mathrm{T}$ cell, $\mathrm{CD} 8^{+} \mathrm{T}$ cell and $\mathrm{CD} 4^{-} \mathrm{CD} 8^{-}$cell fractions, respectively, at FDR $<0.1$ and absolute coverage-corrected mean methylation difference $>0.1$ (Fig. 2, Table 1, ESM Table 3-5).

In the $\mathrm{CD}^{+}{ }^{+} \mathrm{T}$ cells, the DMC located in the intergenic region between TRAF3 and RCOR1 was hypomethylated in cases. Furthermore, three highly significant DMCs were found at the promoters of protein-coding genes: $R G P D 8, F O X R 1$ and $A R R D C 2$. A variant in $A R R D C 2$ has been genetically associated with early-onset Crohn's disease [27]. In $\mathrm{CD}^{+} \mathrm{T}$ cells, the most significant DMC was located in the intergenic region between the pseudogene LOC390705 and a non-coding RNA, LOC113002582. In the $\mathrm{CD}^{-} \mathrm{CD}^{-}$cell fraction, highly significant differences in methylation were observed near proteincoding genes WDR7 and EXOC5 (Table 1).
Further, to gain insights into biological functions of the genes near DMCs, we performed GO pathway enrichment analysis (Fisher's exact test) on the sets of the nearest genes for each cell type. For $\mathrm{CD}^{+} \mathrm{T}$ cells, two GO terms were enriched: peptidyl-tyrosine phosphorylation $(\mathrm{FDR}=0.035)$ and cell differentiation $(\mathrm{FDR}=0.045)$. No GO terms were significantly enriched among the nearest genes for $\mathrm{CD}^{+} \mathrm{T}$ cells or $\mathrm{CD}^{-} \mathrm{CD} 8^{-}$cell fractions.

Most of the DMRs were cell type-specific Although a single $\mathrm{CpG}$ site might affect gene expression, often adjacent $\mathrm{CpG}$ sites may act together in gene expression regulation [28]. Such DMCs can be combined into a differentially methylated region (DMR). Therefore, we combined individual DMCs within $2 \mathrm{~kb}$ with consistent methylation patterns into DMRs. We identified 79, 56 and 45 DMRs between the cases and controls in the $\mathrm{CD}^{+}{ }^{+} \mathrm{T}$ cell, $\mathrm{CD} 8^{+} \mathrm{T}$ cell and $\mathrm{CD} 4^{-} \mathrm{CD} 8^{-}$cell fractions, respectively (Fig. 3a, ESM Table 6-8). While the majority of DMRs were cell type-specific, three DMRs near the FOXR1, RGPD8 and LOC100128946 (also known as LINC01310) genes were hypermethylated and one DMR near the LOC390705 pseudogene was hypomethylated in cases in all three cell fractions. These results suggest that differences in these three DMRs are conserved across cell types. It is also possible that DNA methylation at these DMRs regulates the expression of genes with a similar functional role in all three subsets. 
a

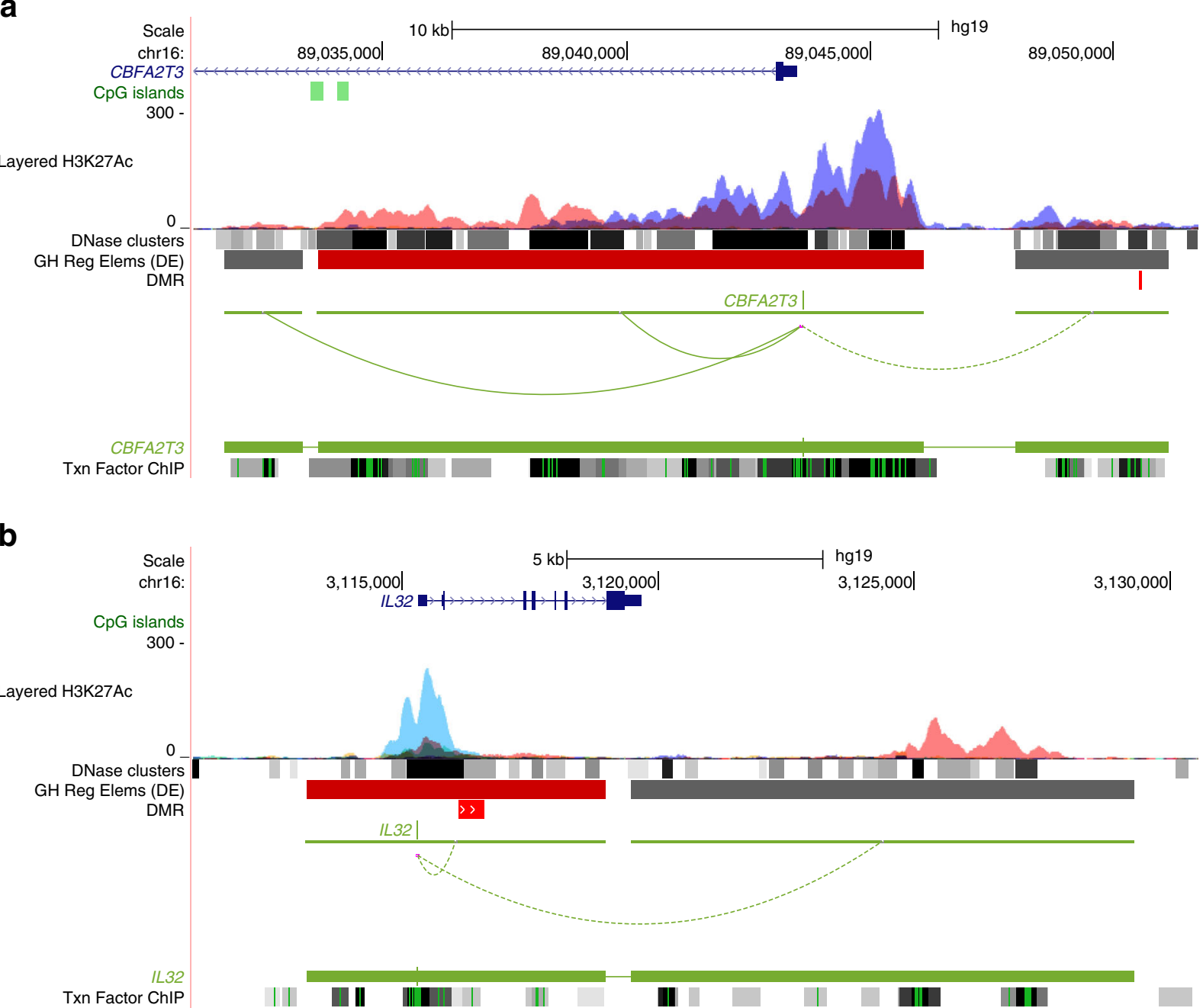

C

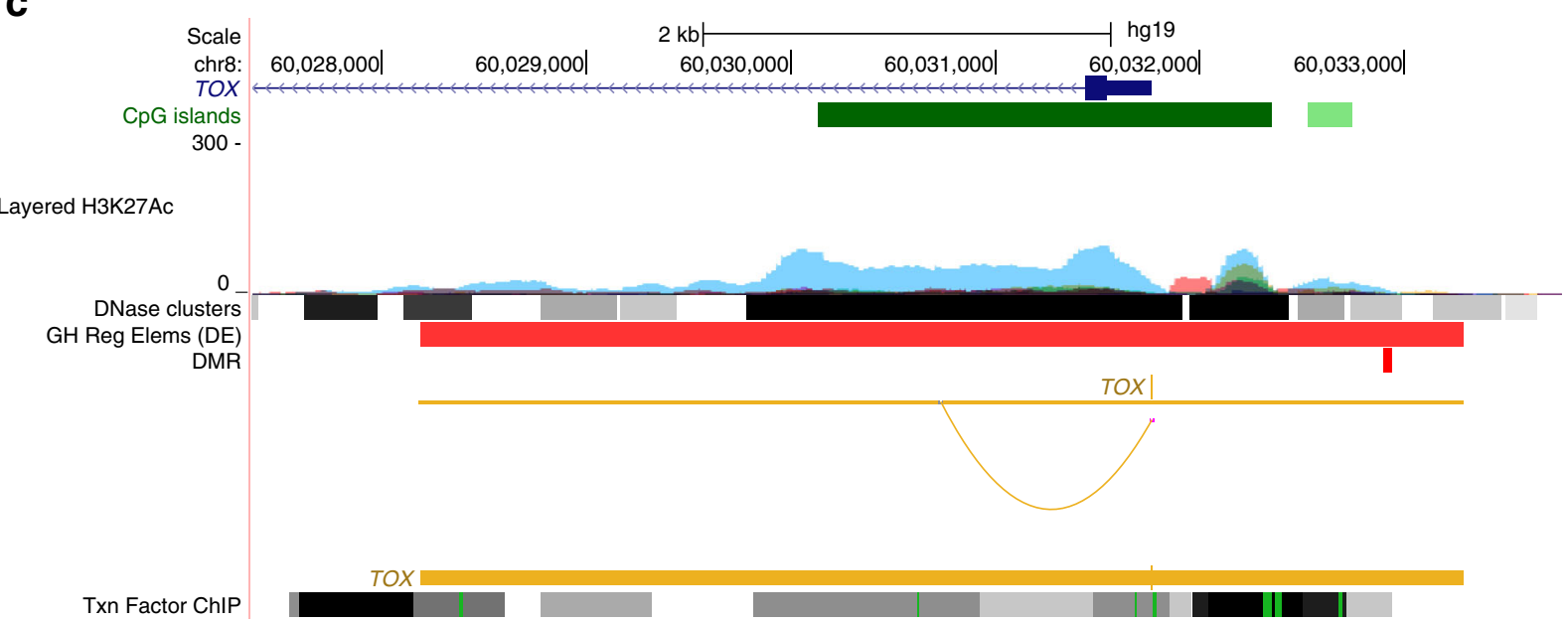

DMRs were distributed across different genomic regions We characterised DMRs with respect to genomic regions (Fig. $3 b)$. In all three fractions, the majority of DMRs were located in intergenic regions $\left(47 \%\right.$ in $\mathrm{CD}^{+} \mathrm{T}$ cells, $39 \%$ in $\mathrm{CD}^{+} \mathrm{T}$ cells and $44 \%$ in the $\mathrm{CD} 4^{-} \mathrm{CD} 8^{-}$cell fraction).
Introns accounted for $25 \%$ and $29 \%$ in $\mathrm{CD}^{+}$and $\mathrm{CD}^{+} \mathrm{T}$ cells, respectively, whereas approximately $20 \%$ of all DMRs were located in promoters in both fractions. However, in contrast to $\mathrm{CD}^{+}$and $\mathrm{CD} 8^{+} \mathrm{T}$ cells, the number of DMRs in promoter regions in $\mathrm{CD} 4^{-} \mathrm{CD} 8^{-}$cell 
Fig. 4 Annotations of the type 1 diabetes-associated DMRs. The genomic loci harbouring the DMRs at CBFA2T3, IL32 and TOX were visualised with the UCSC Genome Browser. The DMRs are shown in red colour in the DMR track below the GeneHancer track in all of the panels. Six other reference tracks are displayed. (a) A DMR hypermethylated in cases vs controls (chr16:89050538-89,050,592) mapped in the intergenic region upstream of $C B F A 2 T 3$ in $\mathrm{CD}^{+} \mathrm{T}$ cells. It overlaps with an enhancer region. A long-distance chromatin interaction between this active regulatory element and $C B F A 2 T 3$ promoter is shown by a dashed line. (b) A DMR hypomethylated in cases vs controls at IL32 gene locus (chr16:3116115-3,116,616) in $\mathrm{CD}^{+} \mathrm{T}$ cells is located at the promoter of the gene. (c) A DMR hypermethylated in cases vs controls in $\mathrm{CD}^{+} \mathrm{T}$ cells (chr8:60032900-60,032,942) is located approximately $1 \mathrm{~kb}$ upstream of TOX and overlaps with its promoter. GH Reg Elems (DE), GeneHancer regulatory elements and gene interactions (Double Elite); Txn Factor ChIP, Transcription factor chromatin immunoprecipitation sequencing clusters

fractions constituted up to $30 \%$. In total, $9-11 \%$ of DMRs were located in exons in all three cell fractions.

The GeneHancer database was utilised to explore DMRs in the enhancer regions. Ten, four and seven DMRs were located in enhancer regions in $\mathrm{CD} 4^{+} \mathrm{T}$ cells, $\mathrm{CD} 8^{+} \mathrm{T}$ cells and the $\mathrm{CD} 4^{-} \mathrm{CD} 8^{-}$cell fractions, respectively (ESM Tables 6-8). The DMR near CBFA2T3 is a part of an enhancer that interacts with its promoter based on the GeneHancer database and may regulate its expression (Fig. 4a). CBFA2T3 encodes a transcriptional repressor and plays a role in $\mathrm{T}$ cell development. A variant of this gene has been associated with autoimmune vitiligo [29]. We also found DMRs near extended promoter regions of several genes including TOX and IL32 (Fig. 4b, c, ESM Tables 6-8) in the $\mathrm{CD} 4^{+}$and $\mathrm{CD} 8^{+} \mathrm{T}$ cell fractions, respectively. Interestingly, of the 47, 33 and 17 stand-alone DMCs, which were not part of DMRs, 12, ten and four were in the promoter or enhancer regions in $\mathrm{CD}^{+} \mathrm{T}$ cells, $\mathrm{CD} 8^{+} \mathrm{T}$ cells and the $\mathrm{CD} 4^{-} \mathrm{CD} 8^{-}$cell fractions, respectively (ESM Table 3-5).
High correlation between methylation and gene expression highlighted candidate genes of interest The availability of RNA-seq data from the purified cell fractions of the very same samples allowed us to assess a possible functional impact of the discovered DMCs on gene expression. We examined correlations between DNA methylation and gene expression, utilising our earlier published RNA-seq data [16] (ESM Tables 3-5, 911). We focused on DMCs that had a high Spearman rank correlation coefficient $(>|0.5|)$ with gene expression (Table 2, Fig. 5). For example, in $\mathrm{CD}^{+} \mathrm{T}$ cells, we found two DMCs on the intron of $D G K Q$ positively correlated with the expression of the gene (Table 2, Fig. 5a). Next, four DMCs on the intron of $P C B P 3$, which is a probable enhancer region, showed an inverse correlation with its expression (Fig. 5b, Table 2). A DMC at the exon of LOC642852 (also known as LINC00205) showed an inverse correlation with the expression of the POFUT2 gene, which is approximately $30 \mathrm{~kb}$ away from the DMC. POFUT2 encodes a fucosyltransferase (FUT), responsible for protein O-fucosylation, a post-translational modification process. Interestingly, a genetic risk variant for type 1 diabetes at FUT2, another FUT of a closely related family, was reported previously [30-32].

In $\mathrm{CD} 8^{+} \mathrm{T}$ cells, there were only two DMCs with a Spearman rank correlation $>|0.5|$. The DMC on chromosome 16 in the intron of $L O C 100134368$ had an inverse correlation with expression of TMEM8A (also known as PGAP6), which is approximately $2 \mathrm{~kb}$ away from the DMC (Fig. 5c, Table 2). Another DMC in the exon of ADAM8 correlated inversely with the expression of this gene (Fig. $5 \mathrm{~d}$, Table 2).

Further, we analysed $\mathrm{CpG}$ sites in our study for already published cis-eQTM associations, using data from a Dutch biobank of cis-eQTM effects based on 3841 whole blood samples [24] (ESM Tables 3-5, 9-11). The expression quantitative trait methylation (eQTM) effects were discovered with the $450 \mathrm{~K}$ DNA methylation array, which covers approximately $5 \%$ of $\mathrm{CpG}$ sites identified in our study. Among those available, we

Table 2 DMCs across all longitudinal time points showing the highest Spearman rank correlation $>|0.5|$ with gene expression levels

\begin{tabular}{|c|c|c|c|c|c|c|c|}
\hline DMC (hg19) & Fraction & Methylation difference & $p$ value & FDR & Nearest gene & Spearman correlation & Correlating gene \\
\hline chr4:961599 & $\mathrm{CD} 4^{+}$ & 0.127 & $7.29 \times 10^{-5}$ & $4.18 \times 10^{-2}$ & $D G K Q$ & 0.619 & $D G K Q$ \\
\hline chr4:962384 & $\mathrm{CD} 4^{+}$ & 0.136 & $4.66 \times 10^{-5}$ & $3.25 \times 10^{-2}$ & $D G K Q$ & 0.508 & $D G K Q$ \\
\hline chr21:47307692 & $\mathrm{CD} 4^{+}$ & -0.171 & $1.33 \times 10^{-5}$ & $1.59 \times 10^{-2}$ & PCBP3 & -0.591 & $P C B P 3$ \\
\hline $\operatorname{chr} 21: 47307758$ & $\mathrm{CD} 4^{+}$ & -0.210 & $2.25 \times 10^{-4}$ & $7.82 \times 10^{-2}$ & PCBP3 & -0.537 & $P C B P 3$ \\
\hline $\operatorname{chr} 21: 47308375$ & $\mathrm{CD} 4^{+}$ & -0.244 & $3.46 \times 10^{-4}$ & $9.76 \times 10^{-2}$ & РCBP3 & -0.537 & РCВP3 \\
\hline $\operatorname{chr} 21: 47308422$ & $\mathrm{CD}^{+}{ }^{+}$ & -0.208 & $3.80 \times 10^{-6}$ & $7.98 \times 10^{-3}$ & РCВP3 & -0.517 & РCBP3 \\
\hline $\operatorname{chr} 21: 46714810$ & $\mathrm{CD}^{+}{ }^{+}$ & -0.109 & $2.66 \times 10^{-6}$ & $6.57 \times 10^{-3}$ & LOC642852 & -0.561 & POFUT2 \\
\hline $\operatorname{chr} 7: 76129434$ & $\mathrm{CD}^{+}{ }^{+}$ & -0.165 & $1.29 \times 10^{-4}$ & $5.64 \times 10^{-2}$ & $D T X 2$ & -0.539 & $U P K 3 B$ \\
\hline $\operatorname{chr} 16: 433855$ & $\mathrm{CD}^{+}$ & -0.174 & $1.14 \times 10^{-9}$ & $1.10 \times 10^{-4}$ & LOC100134368 & -0.538 & TMEM8A \\
\hline $\operatorname{chr10:135092506}$ & $\mathrm{CD}^{+}$ & -0.118 & $5.12 \times 10^{-6}$ & $3.96 \times 10^{-2}$ & ADAM8 & -0.520 & ADAM8 \\
\hline chr4:961576 & $\mathrm{CD}^{-} \mathrm{CD}^{-}$ & 0.164 & $2.01 \times 10^{-6}$ & $2.65 \times 10^{-2}$ & $D G K Q$ & 0.654 & $D G K Q$ \\
\hline chr4:961573 & $\mathrm{CD}^{-} \mathrm{CD}^{-}$ & 0.119 & $2.37 \times 10^{-5}$ & $9.88 \times 10^{-2}$ & $D G K Q$ & 0.528 & $D G K Q$ \\
\hline
\end{tabular}


a

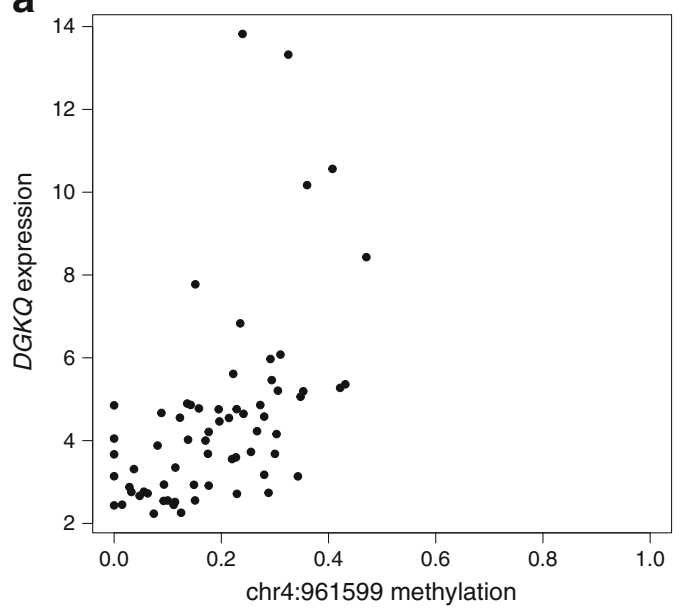

C

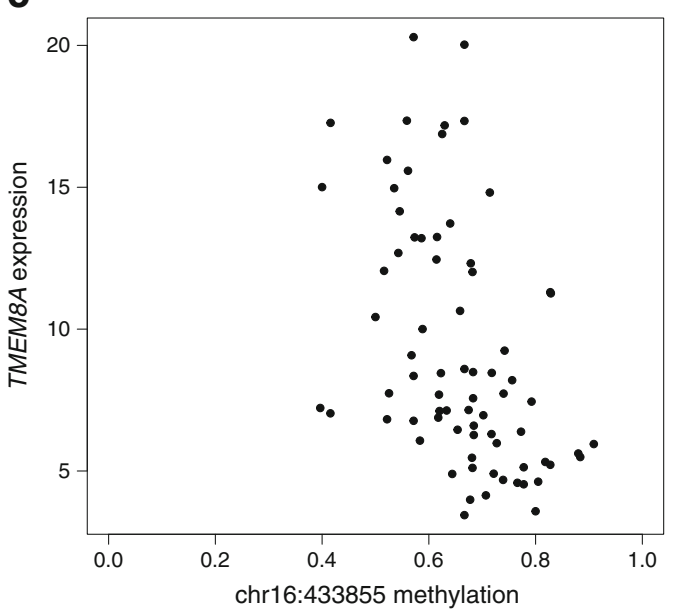

Fig. 5 Methylation and gene expression correlation analysis. The most highly correlated expression-methylation pairs in $\mathrm{CD} 4^{+}$and $\mathrm{CD} 8^{+} \mathrm{T}$ cells. Spearman $\rho$ (Spearman's rank correlation coefficient) is between methylation proportion ( $x$-axis) and reads per kb per million (RPKM)normalised gene expression level ( $y$-axis). (a, b) Expression-methylation pairs in the $\mathrm{CD}^{+} \mathrm{T}$ cells. The methylation of CpG site chr4:961599 at an intron of $D G K Q$ gene positively correlated (Spearman $\rho=0.619$ ) with gene expression. The methylation of $\mathrm{CpG}$ site chr21: 47307692 at an

found three DMCs with known eQTM effects: chr4:81128398 near PRDM8 (cg05474265) and chr8:144808965 at FAM83H (cg09380067) in $\mathrm{CD}^{+} \mathrm{T}$ cells, and chr2:73496203 at FBXO41 (cg21918313) in the $\mathrm{CD}^{-} \mathrm{CD}^{-}$cell fraction (ESM Tables 3-5, 9-11). The observed direction of expression-methylation correlation in our data was in line with the eQTM effect at $\mathrm{CpG}$ sites near PRDM8 and FBXO41.

Pre-seroconversion analysis revealed DNA methylation differences at a very early stage of type 1 diabetes In addition to the differential methylation analysis of all longitudinal samples, we analysed DNA methylation in the samples taken before seroconversion to identify changes that occur prior to detection of islet autoantibodies. We refer to this analysis as pre-seroconversion b

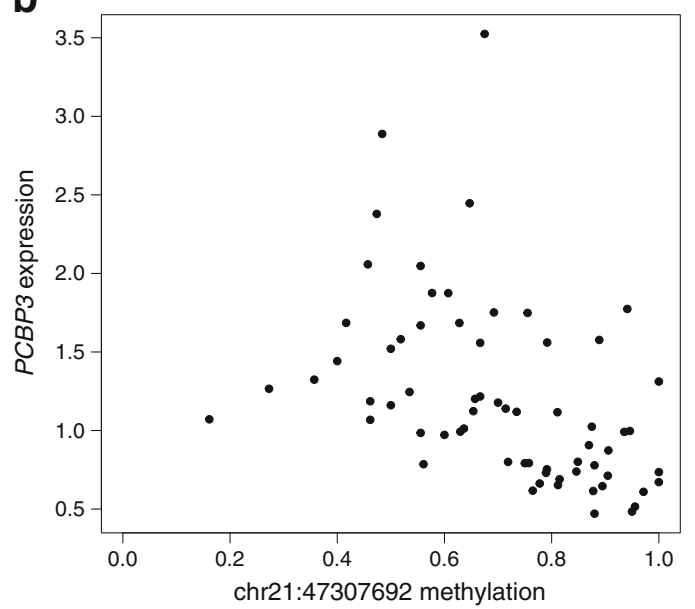

d

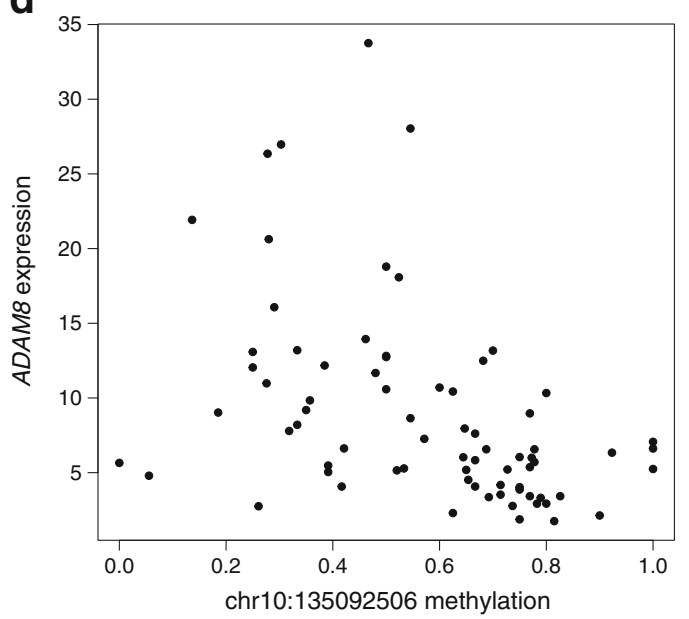

intron of $P C B P 3$ gene showed negative correlation (Spearman $\rho=$ -0.591) with gene expression. (c, d) Expression-methylation pairs in the $\mathrm{CD} 8^{+} \mathrm{T}$ cells. The methylation of $\mathrm{CpG}$ site chr16:433855 near TMEM $8 A$ gene inversely correlated (Spearman $\rho=-0.538$ ) with gene expression. The methylation of $\mathrm{CpG}$ site chr10:135092506 at an exon of $A D A M 8$ gene showed negative correlation (Spearman $\rho=-0.520$ ) with gene expression. For a complete list of $\mathrm{CpG}$ sites and their correlation with gene expression, please see ESM Tables 3-5, 9-11

analysis. Unless specified, the differential methylation analysis refers to the analysis where we take all the longitudinal time points into consideration. We identified 249, 144 and 143 DMCs between cases and controls in the $\mathrm{CD} 4^{+} \mathrm{T}$ cell, $\mathrm{CD} 8^{+} \mathrm{T}$ cell and $\mathrm{CD}^{-} \mathrm{CD}^{-}$cell fractions, respectively (FDR $<0.1$ and coverage-corrected mean methylation difference $>0.1$ ) (ESM Tables 9-11). The numbers of DMRs between cases and controls discovered before seroconversion were 97, 68 and 63 in the $\mathrm{CD}^{+}{ }^{-}$cell, $\mathrm{CD} 8^{+} \mathrm{T}$ cell and $\mathrm{CD} 4^{-} \mathrm{CD} 8^{-}$cell fractions, respectively (ESM Tables 12-14). Importantly, the overlay of DMRs identified in all longitudinal samples and DMRs discovered prior to the appearance of autoantibodies (Fig. 6a) revealed that the majority of DMRs were pre-seroconversion-specific. We found 58,52 and 48 pre-seroconversion-specific DMRs in $\mathrm{CD}^{+} \mathrm{T}$ cell, 
a

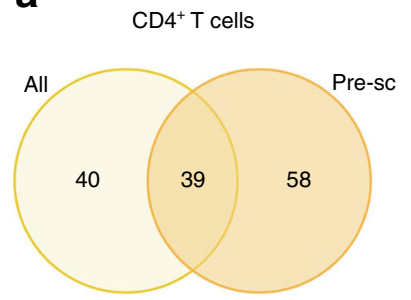

CD8 ${ }^{+} \mathrm{T}$ cells

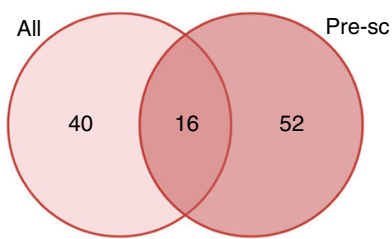

CD4-8- cell fraction

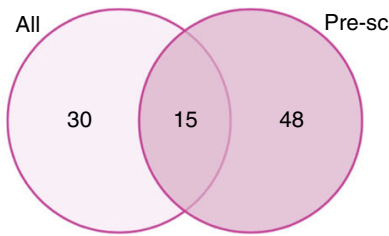

b

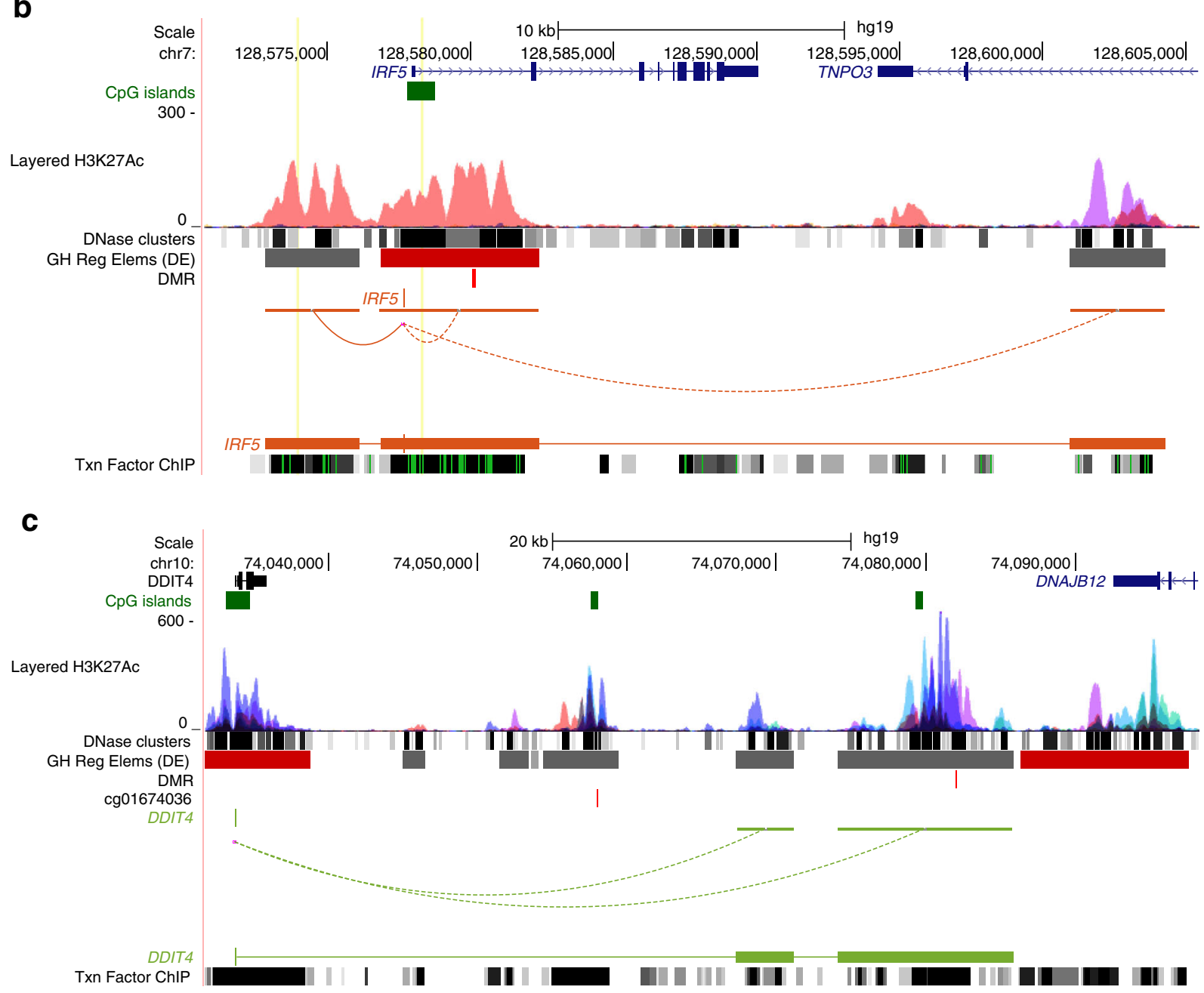

Fig. 6 DNA methylation analysis prior to seroconversion. (a) Venn diagrams of the numbers of DMRs detected in different cell fractions for all longitudinal samples (indicated as All) and prior to seroconversion (indicated as Pre-sc). A DMR is considered to be found in two analyses if at least one DMC within the DMR is found in both cell fractions. Seroconversion was defined based on the measurements of autoantibodies IAA, GADA, IA-2A and ZnT8A in the participant's serum (details in the Methods section). The figure was created with BioRender. (b) UCSC Genome Browser visualisation of a DMR hypermethylated in cases vs control participants at IRF5 gene identified in $\mathrm{CD}^{+} \mathrm{T}$ cells prior to seroconversion. The genomic locus (chr7:128568936-128,609,758) includes the DMR (chr7:128580072-128,580,230). (c) The DMR

$\mathrm{CD}^{+} \mathrm{T}$ cell and $\mathrm{CD} 4^{-} \mathrm{CD} 8^{-}$cell fractions, respectively. These DMRs were not identified in the analysis across all longitudinal time points. (chr10:74082048-74,082,090) identified in this study and the DMC (chr10:74058002, cg01674036) found in the Paul et al study [12] located in the intergenic region between DDIT4 and DNAJB12 in $\mathrm{CD}^{+} \mathrm{T}$ cells prior to seroconversion; the DMC is shown below the DMR track, and the DMC and DMR are shown as vertical lines in respective tracks. Six other reference tracks are displayed. Long-distance chromatin interactions between the gene promoter and other active regulatory elements (indicated in grey colour in GeneHancer regulatory element track) are shown by curves connecting promoters and other regulatory elements. GH Reg Elems (DE), GeneHancer regulatory elements and gene interactions (Double Elite); Txn Factor ChIP, Transcription factor chromatin immunoprecipitation sequencing clusters

In $\mathrm{CD}^{+} \mathrm{T}$ cells, the most significant $\mathrm{DMC}$ was found at the promoter of $A R R D C 2$ gene and was hypomethylated in cases vs controls (Table 3). This DMC was also one of the 
Table 3 Top-ranked DMCs at FDR $<0.0001$ identified between cases and controls prior to seroconversion

\begin{tabular}{|c|c|c|c|c|c|c|}
\hline DMC (hg19) & Fraction & Methylation difference & $p$ value & FDR, $<0.0001$ & Nearest gene & Genomic region \\
\hline $\operatorname{chr19:18118304}$ & $\mathrm{CD} 4^{+}$ & -0.185 & $4.22 \times 10^{-22}$ & $1.64 \times 10^{-16}$ & $A R R D C 2$ & Promoter \\
\hline chr7:3169658 & $\mathrm{CD}^{+}{ }^{+}$ & 0.269 & $4.76 \times 10^{-13}$ & $4.62 \times 10^{-8}$ & BC038729 & Intergenic \\
\hline chr10:99209697 & $\mathrm{CD} 4^{+}$ & 0.541 & $1.95 \times 10^{-12}$ & $1.52 \times 10^{-7}$ & ZDHHC16 & Intron \\
\hline chr14:65542789 & $\mathrm{CD} 4^{+}$ & -0.505 & $7.00 \times 10^{-12}$ & $3.88 \times 10^{-7}$ & LOC100506321 & Intron \\
\hline chr8:530556 & $\mathrm{CD} 4^{+}$ & -0.171 & $1.00 \times 10^{-11}$ & $4.87 \times 10^{-7}$ & $T D R P$ & Intergenic \\
\hline chr21:47285711 & $\mathrm{CD}^{+}$ & -0.124 & $9.16 \times 10^{-22}$ & $4.78 \times 10^{-16}$ & PCBP3 & Intron \\
\hline $\operatorname{chr17:71322457}$ & $\mathrm{CD}^{+}$ & -0.113 & $1.92 \times 10^{-11}$ & $2.28 \times 10^{-6}$ & $C D C 42 E P 4$ & Intergenic \\
\hline $\operatorname{chr19:12035022}$ & $\mathrm{CD}^{+}$ & -0.150 & $3.10 \times 10^{-10}$ & $2.31 \times 10^{-5}$ & ZNF700 & Promoter \\
\hline $\operatorname{chr} 7: 3169674$ & $\mathrm{CD} 8^{+}$ & -0.174 & $3.00 \times 10^{-10}$ & $2.31 \times 10^{-5}$ & BC038729 & Intergenic \\
\hline $\operatorname{chr} 14: 45343058$ & $\mathrm{CD}^{+}$ & 0.189 & $6.22 \times 10^{-10}$ & $4.33 \times 10^{-5}$ & C14orf 28 & Intergenic \\
\hline $\operatorname{chr11:134709660~}$ & $\mathrm{CD}^{-} \mathrm{CD}^{-}$ & 0.228 & $5.41 \times 10^{-17}$ & $4.72 \times 10^{-11}$ & $A K 125040$ & Intergenic \\
\hline chr2:113192534 & $\mathrm{CD}^{-} \mathrm{CD}^{-}$ & 0.132 & $6.45 \times 10^{-13}$ & $1.87 \times 10^{-7}$ & $R G P D 8$ & Promoter \\
\hline chr8:144788521 & $\mathrm{CD} 4^{-} \mathrm{CD} 8^{-}$ & 0.18 & $1.09 \times 10^{-12}$ & $2.37 \times 10^{-7}$ & $C C D C 166$ & Intron \\
\hline chr3:194706028 & $\mathrm{CD} 4^{-} \mathrm{CD} 8^{-}$ & -0.135 & $9.52 \times 10^{-12}$ & $1.38 \times 10^{-6}$ & XXYLT1 & Intergenic \\
\hline chr6:163570666 & $\mathrm{CD} 4^{-} \mathrm{CD} 8^{-}$ & -0.219 & $5.53 \times 10^{-10}$ & $4.25 \times 10^{-5}$ & $A K 296276$ & Intron \\
\hline
\end{tabular}

most significant findings in the analysis of all longitudinal samples (Table 1). In $\mathrm{CD}^{+} \mathrm{T}$ cells, the most significant $\mathrm{DMC}$ was observed at the intron of the $P C B P 3$ gene. This $\mathrm{CpG}$ site is located in the plausible enhancer region (GeneHancer database) and may regulate the expression of $P C B P 3$. Furthermore, methylation-expression analysis revealed a high correlation between methylation at $P C B P 3$ and expression of the gene (Table 4).

Notably, in $\mathrm{CD}^{+} \mathrm{T}$ cells we identified hypermethylation in case compared with control participants at the promoter of the transcription factor IRF5 and DNAJB12 (Fig. 6b, c, ESM Table 12).

Several DMCs were validated using pyrosequencing analysis in a subset of samples The RRBS results were validated by bisulphite pyrosequencing of the $\mathrm{CD}^{+}$and $\mathrm{CD}^{+} \mathrm{T}$ cells of three case-control pairs from the same cohort. We selected nine DMCs in $\mathrm{CD}^{+} \mathrm{T}$ cells and one $\mathrm{DMC}$ in $\mathrm{CD}^{+} \mathrm{T}$ cells based on statistical significance and the consistency of pairwise methylation difference profiles.

The direction of methylation difference was concordant between RRBS and bisulphite pyrosequencing results for eight out of ten selected targets (Table 5). High positive correlations between RRBS and pyrosequencing results were observed for CpG sites near ARRDC2 (chr19:18118304), PCBP3 (chr21:47307815) and TRAF3 (chr14:81128398) and also at the intergenic $\mathrm{CpG}$ site near PRDM8 (chr4:81128398) with a known eQTM effect on the gene expression. In the $\mathrm{CD}^{+} \mathrm{T}$ cells, we validated the DMC near IL32 (chr16:3116115), which was hypomethylated on the promoter region in type 1 diabetes, compared with control participants.

\section{Discussion}

In this study, we identified DNA methylation changes in children developing type 1 diabetes, compared with their matched control participants, before diabetes diagnosis and even before the appearance of autoantibodies associated with type 1 diabetes. Analysing fractionated PBMC samples allowed us to discover immune cell subset-specific DNA methylation changes. Importantly, DNA methylation changes were observed in genes associated with type 1 diabetes, including IL32, TRAF3 and DGKQ, and in novel candidate genes, which have not been linked to the disease, such as ARRDC2 and $P C B P 3$. Using pyrosequencing we validated the direction of methylation difference identified by RRBS for eight out of ten selected targets. Since the number of case individuals in this prospective study cohort was limited $(n=7)$, we selected matched control individuals to control for effects of confounding factors, such as sex and place of birth. The risk of error was further minimised by analysing several time points for each individual. Even with these measures taken, the number of individuals is an important limitation of this study, and the results need to be validated in a larger cohort.

A strength of our study is the correlation of DNA methylation with gene expression from the purified cell type of the very same samples from our earlier report [16], which enabled us to highlight candidate genes whose expression might be influenced by differential methylation. For instance, an intron of $P C B P 3$ had a locus hypomethylated in cases in $\mathrm{CD}^{+} \mathrm{T}$ cells across all time points and in $\mathrm{CD}^{+} \mathrm{T}$ cells before seroconversion, and it had an inverse correlation with the gene expression. RNA binding proteins of the poly(rC) binding protein $(\mathrm{PCBP})$ family are important in regulating gene 
Table 4 DMCs in the analysis of only pre-seroconversion samples showing the highest Spearman rank correlation $>|0.5|$ with gene expression levels

\begin{tabular}{|c|c|c|c|c|c|c|c|}
\hline DMC (hg19) & Fraction & Methylation difference & $p$ value & FDR & Nearest gene & Spearman correlation & Correlating gene \\
\hline chr2:1817466 & $\mathrm{CD}^{+}{ }^{+}$ & 0.269 & $1.88 \times 10^{-4}$ & $8.42 \times 10^{-2}$ & MYTIL & -0.695 & $P X D N$ \\
\hline chr2:1817753 & $\mathrm{CD}^{+}$ & 0.174 & $9.85 \times 10^{-5}$ & $6.05 \times 10^{-2}$ & MYTIL & -0.629 & $P X D N$ \\
\hline chr16:452426 & $\mathrm{CD}^{+}$ & -0.124 & $7.79 \times 10^{-7}$ & $3.36 \times 10^{-3}$ & DECR2 & -0.623 & $L A 16 c-O S 12.2$ \\
\hline chr8:144659988 & $\mathrm{CD}^{+}$ & 0.104 & $1.43 \times 10^{-4}$ & $7.35 \times 10^{-2}$ & NAPRT1 & -0.600 & NAPRT1 \\
\hline $\operatorname{chr11:67351952}$ & $\mathrm{CD}^{+}$ & -0.104 & $1.92 \times 10^{-5}$ & $2.53 \times 10^{-2}$ & GSTP1 & -0.567 & GSTP1 \\
\hline chr5:179193600 & $\mathrm{CD}^{+}$ & -0.197 & $4.95 \times 10^{-5}$ & $4.17 \times 10^{-2}$ & LTC4S & -0.548 & $R U F Y 1$ \\
\hline $\operatorname{chr19:37807762~}$ & $\mathrm{CD}^{+}{ }^{+}$ & 0.138 & $1.49 \times 10^{-5}$ & $2.17 \times 10^{-2}$ & HKRl & -0.540 & ZNF527 \\
\hline $\operatorname{chr} 7: 76129273$ & $\mathrm{CD}^{+}{ }^{+}$ & -0.174 & $3.28 \times 10^{-5}$ & $3.34 \times 10^{-2}$ & DTX2 & -0.536 & $U P K 3 B$ \\
\hline chr2:131695535 & $\mathrm{CD}^{+}$ & -0.214 & $6.79 \times 10^{-5}$ & $5.00 \times 10^{-2}$ & ARHGEF4 & 0.600 & FAM168B \\
\hline chr4:961405 & $\mathrm{CD}^{+}{ }^{+}$ & 0.325 & $1.29 \times 10^{-6}$ & $4.84 \times 10^{-3}$ & $D G K Q$ & 0.504 & $D G K Q$ \\
\hline chr8:144660722 & $\mathrm{CD}^{+}$ & 0.142 & $2.53 \times 10^{-6}$ & $1.87 \times 10^{-2}$ & NAPRT1 & -0.543 & NAPRT1 \\
\hline $\operatorname{chr} 21: 47307825$ & $\mathrm{CD} 8^{+}$ & -0.142 & $5.84 \times 10^{-5}$ & $9.98 \times 10^{-2}$ & PCBP3 & -0.534 & PCBP3 \\
\hline $\operatorname{chr} 21: 47285711$ & $\mathrm{CD} 8^{+}$ & -0.427 & $9.16 \times 10^{-22}$ & $4.78 \times 10^{-16}$ & PCBP3 & -0.512 & PCBP3 \\
\hline chr21:47307753 & $\mathrm{CD} 8^{+}$ & -0.129 & $6.48 \times 10^{-9}$ & $3.38 \times 10^{-4}$ & PCBP3 & -0.501 & РСВР3 \\
\hline $\operatorname{chr17:71322457}$ & $\mathrm{CD} 8^{+}$ & 0.548 & $1.92 \times 10^{-11}$ & $2.28 \times 10^{-6}$ & $C D C 42 E P 4$ & 0.516 & SLC39A11 \\
\hline $\operatorname{chr11:65359968}$ & $\mathrm{CD}^{-} \mathrm{CD}^{-}$ & -0.320 & $6.92 \times 10^{-9}$ & $3.14 \times 10^{-4}$ & KCNK7 & -0.545 & LTBP3 \\
\hline chr16:1480869 & $\mathrm{CD}^{-} \mathrm{CD}^{-}$ & 0.135 & $7.38 \times 10^{-6}$ & $3.04 \times 10^{-2}$ & C16orf91 & 0.611 & TSR3 \\
\hline $\operatorname{chr1:3811367}$ & $\mathrm{CD}^{-} \mathrm{CD}^{-}$ & 0.238 & $9.27 \times 10^{-10}$ & $5.77 \times 10^{-5}$ & Clorf174 & 0.558 & $D F F B$ \\
\hline chr19:50962487 & $\mathrm{CD}^{-} \mathrm{CD}^{-}$ & 0.121 & $5.31 \times 10^{-5}$ & $9.00 \times 10^{-2}$ & EMC10 & 0.527 & KCNC3 \\
\hline chr19:1047251 & $\mathrm{CD}^{-} \mathrm{CD}^{-}$ & 0.171 & $4.93 \times 10^{-5}$ & $8.68 \times 10^{-2}$ & $A B C A 7$ & 0.501 & $A T P 5 D$ \\
\hline
\end{tabular}

expression at the post-transcriptional level. Further, another locus at the promoter of IL32 was also hypomethylated in cases compared with controls in the analysis of all longitudinal samples in $\mathrm{CD}^{+} \mathrm{T}$ cells. Methylation-expression analysis showed a weak inverse correlation between IL32 mRNA expression and promoter methylation, suggesting that epigenetic changes at the promoter of IL32 lead to a higher expression of this cytokine. Interestingly, IL-32 was significantly upregulated at the mRNA level in cases compared with controls in this cohort. IL-32, a proinflammatory cytokine,

Table 5 Validation of the RRBS results by bisulphite pyrosequencing

\begin{tabular}{|c|c|c|c|c|c|c|c|c|c|}
\hline \multicolumn{6}{|c|}{ Selected targets for validation } & \multicolumn{4}{|l|}{ Validation results } \\
\hline DMC (hg19) & $\begin{array}{l}\text { Nearest } \\
\text { gene }\end{array}$ & $\begin{array}{l}\text { Methylation } \\
\text { difference }\end{array}$ & $p$ value & FDR & Fraction & $\begin{array}{l}\text { Concordant direction of } \\
\text { difference }\end{array}$ & Correlation & $\begin{array}{l}p \\
\text { value }\end{array}$ & FDR \\
\hline $\operatorname{chr19:18118304}$ & $A R R D C 2$ & -0.174 & $1.11 \times 10^{-9}$ & $1.94 \times 10^{-5}$ & $\mathrm{CD}^{+}$ & Yes & 0.85 & 0.03 & 0.15 \\
\hline $\operatorname{chr} 21: 47307815$ & $P C B P 3$ & -0.207 & $7.69 \times 10^{-8}$ & $6.48 \times 10^{-4}$ & $\mathrm{CD}^{+}$ & Yes & 0.86 & 0.03 & 0.15 \\
\hline chr14:103227394 & TRAF3 & -0.15 & $5.86 \times 10^{-10}$ & $1.24 \times 10^{-5}$ & $\mathrm{CD}^{+}$ & Yes & 0.82 & 0.05 & 0.15 \\
\hline chr4:81128398 & PRDM8 & -0.143 & $4.71 \times 10^{-6}$ & $8.92 \times 10^{-3}$ & $\mathrm{CD}^{+}$ & Yes & 0.71 & 0.11 & 0.23 \\
\hline $\operatorname{chr} 1: 228659024$ & Histone3 & 0.147 & $3.33 \times 10^{-8}$ & $3.40 \times 10^{-4}$ & $\mathrm{CD}^{+}$ & Yes & 0.74 & 0.09 & 0.23 \\
\hline $\operatorname{chr} 16: 3116115$ & $I L 32$ & -0.141 & $1.68 \times 10^{-7}$ & $3.82 \times 10^{-3}$ & $\mathrm{CD}^{+}$ & Yes & 0.14 & 0.79 & 0.79 \\
\hline chr22:39633525 & $P D G F B$ & 0.189 & $1.77 \times 10^{-9}$ & $2.61 \times 10^{-5}$ & $\mathrm{CD}^{+}{ }^{+}$ & Yes & 0.62 & 0.19 & 0.32 \\
\hline chr8:60032942 & TOX & 0.113 & $3.20 \times 10^{-5}$ & $2.63 \times 10^{-2}$ & $\mathrm{CD}^{+}{ }^{+}$ & Yes & 0.25 & 0.63 & 0.70 \\
\hline chr18:77398359 & $C T D P 1$ & 0.144 & $2.46 \times 10^{-7}$ & $1.26 \times 10^{-3}$ & $\mathrm{CD}^{+}$ & No & 0.46 & 0.36 & 0.49 \\
\hline chr2:113192477 & $R G P D 8$ & 0.13 & $8.45 \times 10^{-13}$ & $1.25 \times 10^{-7}$ & $\mathrm{CD}^{+}$ & No & 0.43 & 0.39 & 0.49 \\
\hline
\end{tabular}

The first six columns contain information about selected targets. In column 7 we indicate whether the methylation difference between the cases and controls was concordant (to the same direction) in the pyrosequencing results compared with RRBS results. Column 8 contains the Pearson correlation coefficient between pyrosequencing and RRBS results (methylation proportions of the six samples that were pyrosequenced). Columns 9 and 10 contain raw and adjusted $p$ values (FDR), respectively 
was shown to be upregulated at either mRNA or protein level in several autoimmune disorders [33]; however, the precise role of this cytokine remains to be elucidated.

Next, we observed hypermethylation in cases vs controls at a locus near $D G K Q$, which correlated positively with the expression of this gene in $\mathrm{CD} 4^{+} \mathrm{T}$ cells and $\mathrm{CD} 4^{-} \mathrm{CD} 8^{-}$cell fractions. This finding suggests that the differential methylation at $D G K Q$ may result in its higher expression in type 1 diabetes cases. This observation is in line with the results of the transcriptomic analysis of $\mathrm{CD}^{+} \mathrm{T}$ cells from the same cohort [16]. Diacylglycerol kinase theta (DGKQ) is a member of a family of diacylglycerol (DAG) kinases, which have critical roles in $\mathrm{T}$ cell receptor (TCR) signalling [34]. The kinase inversely regulate $\mathrm{T}$ cell activation, by terminating DAG-mediating signalling [35]. Interestingly, a recent integrative analysis of genetic association, functional genomics data and protein-protein networks identified $D G K Q$ as a potential novel type 1 diabetes therapeutic gene target along with other novel and known targets, e.g., IL2RA, IL6ST, IL6R and TYK2 [3].

The type 1 interferon transcriptional signature is associated with the development of type 1 diabetes $[36,37]$. In $\mathrm{CD}^{+} \mathrm{T}$ cells of pre-seroconversion samples, we observed hypermethylation at the promoter of IRF5 (Fig. 6b, ESM Table 12). This DMR is located in the vicinity (less than $7 \mathrm{~kb}$ ) of multiple SNPs that were previously associated with RA [38, 39], systemic lupus erythematosus (SLE) [40, 41] and IBD [42]. This finding suggests that the transcription factor may have a role at the very early stages of islet autoimmunity. Further, in $\mathrm{CD} 8^{+} \mathrm{T}$ cells, we found hypermethylation at an exon of IRF1 gene (ESM Table 7). Interferon regulatory factor 1 (IRF1) is important in the host immune response to pathogens and $\mathrm{CD} 8^{+} \mathrm{T}$ cell maturation [43]. Further, we found hypomethylated DMRs at $T R A F 3$ in $\mathrm{CD}^{+}{ }^{+} \mathrm{T}$ cells and $\mathrm{CD} 4^{-} \mathrm{CD} 8^{-}$cell fractions. $T R A F 3$ is also critical in regulation of type 1 interferon production and plays a role in antiviral immune response [44]. In $\mathrm{CD}^{+} \mathrm{T}$ cells, hypomethylation at TRAF3 had moderate positive correlation with the gene expression (Spearman $\rho=$ 0.334 ), which might result in lower gene expression in cases vs controls. TNF receptor-associated factor 3 (TRAF3) was shown to be recruited in the TCR/CD28 signalling complex in murine $\mathrm{CD}^{+} \mathrm{T}$ cells and critical for $\mathrm{T}$ cell-mediated immunity to infection [45].

Thymocyte selection-associated high mobility group box protein (TOX) is a key transcriptional regulator indispensable for $\mathrm{CD}^{+} \mathrm{T}$ cell development in the thymus [46]. In addition, it drives epigenetic remodelling of $\mathrm{CD} 8^{+} \mathrm{T}$ cells towards an exhausted phenotype in chronic infections [47, 48]. Notably, in the $\mathrm{CD} 4^{+} \mathrm{T}$ cells, we identified a hypermethylation in cases at the intergenic region near the TSS of the TOX gene. The methylation at this region had a weak negative correlation $(-0.157)$ with gene expression, suggesting that hypermethylation of this locus in cases may favour $\mathrm{T}$ cell differentiation towards an effector phenotype in type 1 diabetes patients. It was reported that autoreactive $\mathrm{CD} 8^{+} \mathrm{T}$ cells with an exhaustion-like profile associated with slow type 1 diabetes progression [49] and preservation of beta cell function in type 1 diabetes patients [50]. Further, genetic variants at $T O X$ are among novel risk loci for type 1 diabetes [51].

Our recent study aimed at identifying umbilical cord blood DNA methylation associated with type 1 diabetes progression [19], as well as a previous study by another group [12], did not find any difference in DNA methylation, suggesting that significant DNA methylation differences in children progressing to the disease are not yet present at birth or that they are too subtle to be identified with the current methods and cohort size.

A recent study by Johnson et al examined DNA methylation changes in blood samples longitudinally collected before diagnosis of type 1 diabetes from children enrolled in the prospective DAISY cohort using Illumina $450 \mathrm{~K}$ and EPIC platforms [14]. They observed 28 DMRs associated with later development of the disease. We found no overlap with the CpG sites identified in the study by Johnson et al. This may perhaps be due to different methodologies and to the fact that Johnson et al analysed peripheral whole blood samples, whereas we examined DNA methylation in purified cell fractions of PBMCs. Despite these differences, both studies identified pre-seroconversion changes in DNA methylation, suggesting that these may predict disease progression before the appearance of autoantibodies. However, more studies are needed to validate the findings in independent, larger cohorts, with replication in other populations.

Interestingly, Paul et al [12] identified one DMC (hg19: chr10:74058002) in purified $\mathrm{CD} 4^{+} \mathrm{T}$ cells between individuals with type 1 diabetes and their healthy co-twins in the intergenic region between DDIT4 and DNAJB12. In our study, we found a DMR (chr10:74082048--74,082,090) region hypermethylated in cases in $\mathrm{CD}^{+} \mathrm{T}$ cells in preseroconverted samples located in the same intergenic region (Fig. 6c).

In conclusion, our results provide novel insights into cell type-specific DNA methylation changes associated with type 1 diabetes development. These findings provide the basis for further studies to find an early methylation signature, which may be useful for disease prediction and management.

Supplementary Information The online version contains peer-reviewed but unedited supplementary material available at https://doi.org/10.1007/ s00125-022-05657-x.

Acknowledgements We are grateful to the families for their participation in the DIABIMMUNE study and the clinical personnel for excellent collaboration, work with the families and collection of the samples for the study. We thank M. Hakkarainen and S. Heinonen (Turku Bioscience Centre, University of Turku, Finland) for their excellent technical help. We acknowledge the Turku Bioscience Centre's core facility, the Finnish Functional 
Genomics Centre (FFGC), supported by Biocenter Finland, for their assistance. We also acknowledge the Finnish Centre for Scientific Computing (CSC), Elixir Finland and the Aalto Science-IT project for computational resources. The graphical abstract was created with BioRender.

Data availability The analysed datasets are available through ArrayExpress accession E-MTAB-11088. Due to privacy reasons, the raw data are available through the corresponding author upon reasonable request.

Funding Open Access funding provided by University of Turku (UTU) including Turku University Central Hospital. R Lahesmaa was supported by the Academy of Finland (AoF) (grants 292335, 294337, 319280, $31444,319280,329277,331790$ ) and Business Finland, and grants from JDRF, the Novo Nordisk Foundation (grant NNF19OC0057218), the Sigrid Jusélius Foundation (SJF), the Jane and Aatos Erkko Foundation, the Finnish Diabetes Foundation and the Finnish Cancer Foundation. R Lahesmaa, HL and MK were supported by the AoF Centre of Excellence in Molecular Systems Immunology and Physiology Research (2012-2017), grant 250114 and grant 292482. VT was supported by the Estonian Research Council (grant PRG1428). LLE reports grants from the European Research Council (ERC) (677943), the European Union's Horizon 2020 research and innovation programme (955321), the AoF $(296801,310561,314443,329278,335434$ and 335611) and the SJF. Our research is also supported by the University of Turku Graduate School (UTUGS), Biocenter Finland and the InFLAMES Flagship Programme of the AoF (decision number: 337530). IS was supported by the Turku Doctoral Programme of Molecular Medicine (TuDMM) and the Finnish Diabetes Research Foundation. EL was supported by the TuDMM, the Finnish Cultural Foundation, and the Kyllikki and Uolevi Lehikoinen Foundation. TG was supported by the Academy of Finland (grant 340231).

Author's relationships and activities The authors declare that there are no relationships or activities that might bias, or be perceived to bias, their work.

Contribution statement IS and UUK contributed to data analysis, interpreted the results and wrote the manuscript. EL was responsible for data analysis and contributed to writing. TG and RK were responsible for pyrosequencing analysis. TH and VT played a key role in the DIABIMMUNE study and provided clinical data and samples. SJ, AL and VS participated in data analysis and interpretation. HK contributed to the sample and data acquisition. R. Lund, LLE and HL contributed to data analysis and interpretation. R Lund also participated in supervision of the laboratory work, provided expertise in the bisulphite sequencing. LLE supervised SJ, AL and VS for data analysis and participated in the interpretation of the results. HL supervised EL for data analysis and participated in the interpretation of the results. MK led the DIABIMMUNE study, provided samples and clinical data, initiated the study with R. Lahesmaa, interpreted the results and edited the manuscript. R. Lahesmaa initiated and designed the study setup, supervised the study, interpreted the results and wrote the manuscript. All authors approved the final version. R. Lahesmaa and EL are the guarantors of the study, accept full responsibility for the work, had access to the data and controlled the decision to publish.

Open Access This article is licensed under a Creative Commons Attribution 4.0 International License, which permits use, sharing, adaptation, distribution and reproduction in any medium or format, as long as you give appropriate credit to the original author(s) and the source, provide a link to the Creative Commons licence, and indicate if changes were made. The images or other third party material in this article are included in the article's Creative Commons licence, unless indicated otherwise in a credit line to the material. If material is not included in the article's Creative Commons licence and your intended use is not permitted by statutory regulation or exceeds the permitted use, you will need to obtain permission directly from the copyright holder. To view a copy of this licence, visit http://creativecommons.org/licenses/by/4.0/.

\section{References}

1. Erlich H, Valdes AM, Noble J et al (2008) HLA DR-DQ haplotypes and genotypes and type 1 diabetes risk: analysis of the type 1 diabetes genetics consortium families. Diabetes 57(4):1084-1092. https://doi.org/10.2337/db07-1331

2. Barrett JC, Clayton DG, Concannon P et al (2009) Genome-wide association study and meta-analysis find that over 40 loci affect risk of type 1 diabetes. Nat Genet 41(6):703-707. https://doi.org/10. 1038/ng.381

3. Robertson CC, Inshaw JRJ, Onengut-Gumuscu S et al (2021) Finemapping, trans-ancestral and genomic analyses identify causal variants, cells, genes and drug targets for type 1 diabetes. Nat Genet 53(7):962-971. https://doi.org/10.1038/s41588-021-00880-5

4. Patterson CC, Dahlquist GG, Gyürüs E, Green A, Soltész G (2009) Incidence trends for childhood type 1 diabetes in Europe during 1989-2003 and predicted new cases 2005-20: a multicentre prospective registration study. Lancet 373(9680):2027-2033. https://doi.org/10.1016/S0140-6736(09)60568-7

5. Rewers M, Ludvigsson J (2016) Environmental risk factors for type 1 diabetes. Lancet 387(10035):2340-2348. https://doi.org/10.1016/ S0140-6736(16)30507-4

6. Liu Y, Aryee MJ, Padyukov L et al (2013) Epigenome-wide association data implicate DNA methylation as an intermediary of genetic risk in rheumatoid arthritis. Nat Biotechnol 31(2):142147. https://doi.org/10.1038/nbt.2487

7. McDermott E, Ryan EJ, Tosetto M et al (2016) DNA methylation profiling in inflammatory bowel disease provides new insights into disease pathogenesis. J Crohn's Colitis 10(1):77-86. https://doi.org/ 10.1093/ecco-jcc/jjv176

8. Weber M, Hellmann I, Stadler MB et al (2007) Distribution, silencing potential and evolutionary impact of promoter DNA methylation in the human genome. Nat Genet 39(4):457-466. https://doi. org/10.1038/ng1990

9. Rakyan VK, Beyan H, Down TA et al (2011) Identification of type 1 diabetes-associated DNA methylation variable positions that precede disease diagnosis. PLoS Genet 7(9):e1002300. https://doi. org/10.1371/journal.pgen.1002300

10. Disanto G, Vcelakova J, Pakpoor J et al (2013) DNA methylation in monozygotic quadruplets affected by type 1 diabetes. Diabetologia 56(9):2093-2095. https://doi.org/10.1007/s00125-013-2972-3

11. Stefan M, Zhang W, Concepcion E, Yi Z, Tomer Y (2014) DNA methylation profiles in type 1 diabetes twins point to strong epigenetic effects on etiology. J Autoimmun 50:33-37. https://doi.org/ 10.1016/j.jaut.2013.10.001

12. Paul DS, Teschendorff AE, Dang MAN et al (2016) Increased DNA methylation variability in type 1 diabetes across three immune effector cell types. Nat Commun 7(1):13555. https://doi. org/10.1038/ncomms 13555

13. Belot M-P, Nadéri K, Mille C et al (2017) Role of DNA methylation at the placental RTL1 gene locus in type 1 diabetes. Pediatr Diabetes 18(3):178-187. https://doi.org/10.1111/pedi.12387

14. Johnson RK, Vanderlinden LA, Dong F et al (2020) Longitudinal DNA methylation differences precede type 1 diabetes. Sci Rep 10(1):3721. https://doi.org/10.1038/s41598-020-60758-0

15. Ziegler AG, Rewers M, Simell O et al (2013) Seroconversion to multiple islet autoantibodies and risk of progression to diabetes in children. JAMA 309(23):2473. https://doi.org/10.1001/jama.2013. 6285 
16. Kallionpää H, Somani J, Tuomela S et al (2019) Early detection of peripheral blood cell signature in children developing $\beta$-cell autoimmunity at a young age. Diabetes 68(10):2024-2034. https://doi. org $/ 10.2337 / \mathrm{db} 19-0287$

17. Peet A, Kool P, Ilonen J, Knip M, Tillmann V (2012) Birth weight in newborn infants with different diabetes-associated HLA genotypes in three neighbouring countries: Finland, Estonia and Russian Karelia. Diabetes Metab Res Rev 28(5):455-461. https://doi.org/ 10.1002/dmrr.2303

18. Boyle P, Clement K, Gu H et al (2012) Gel-free multiplexed reduced representation bisulfite sequencing for large-scale DNA methylation profiling. Genome Biol 13(10):R92. https://doi.org/ 10.1186/gb-2012-13-10-r92

19. Laajala E, Ullah U, Grönroos T et al (2021) Umbilical cord blood DNA methylation in children who later develop type 1 diabetes. medRxiv 2021.05.21.21257593. (Preprint). 25 May 2021. Available from: https://doi.org/10.1101/2021.05.21.21257593 (Accessed 9 Dec 2021)

20. Laajala E, Halla-aho V, Grönroos T et al (2021) Permutation-based significance analysis reduces the type 1 error rate in bisulfite sequencing data analysis of human umbilical cord blood samples. bioRxiv 2021.05.18.444359. (Preprint). 3 July 2021. Available from: https://doi.org/10.1101/2021.05.18.444359 (Accessed 9 Dec 2021)

21. R Core Team (2020) R: a language and environment for statistical computing. R Foundation for Statistical Computing, Vienna, Austria

22. Laajala TD, Jumppanen M, Huhtaniemi R et al (2016) Optimized design and analysis of preclinical intervention studies in vivo. Sci Rep 6(1):30723. https://doi.org/10.1038/srep30723

23. Akalin A, Franke V, Vlahoviček K, Mason CE, Schubeler D (2015) Genomation: a toolkit to summarize, annotate and visualize genomic intervals. Bioinformatics 31(7):1127-1129. https://doi.org/10. 1093/bioinformatics/btu775

24. Bonder MJ, Luijk R, Zhernakova DV et al (2017) Disease variants alter transcription factor levels and methylation of their binding sites. Nat Genet 49(1):131-138. https://doi.org/10.1038/ng.3721

25. Flicek P, Ahmed I, Amode MR et al (2012) Ensembl 2013. Nucleic Acids Res 41(D1):D48-D55. https://doi.org/10.1093/nar/gks1236

26. Flicek P, Amode MR, Barrell D et al (2014) Ensembl 2014. Nucleic Acids Res 42(D1):D749-D755. https://doi.org/10.1093/nar/ gkt1196

27. Zeissig S, Petersen B-S, Tomczak M et al (2015) Early-onset Crohn's disease and autoimmunity associated with a variant in CTLA-4. Gut 64(12):1889-1897. https://doi.org/10.1136/gutjnl2014-308541

28. Deaton AM, Bird A (2011) CpG islands and the regulation of transcription. Genes Dev 25(10):1010-1022. https://oi.org/10.1101/ $\operatorname{gad} .2037511$

29. Jin Y, Andersen G, Yorgov D et al (2016) Genome-wide association studies of autoimmune vitiligo identify 23 new risk loci and highlight key pathways and regulatory variants. Nat Genet $48(11)$ : 1418-1424. https://doi.org/10.1038/ng.3680

30. Smyth DJ, Cooper JD, Howson JMM et al (2011) FUT2 nonsecretor status links type 1 diabetes susceptibility and resistance to infection. Diabetes 60(11):3081-3084. https://doi.org/10.2337/db110638

31. Onengut-Gumuscu S, Chen W-M, Burren O et al (2015) Fine mapping of type 1 diabetes susceptibility loci and evidence for colocalization of causal variants with lymphoid gene enhancers. Nat Genet 47(4):381-386. https://doi.org/10.1038/ng.3245
32. Ihara K, Fukano C, Ayabe T et al (2017) FUT2 non-secretor status is associated with type 1 diabetes susceptibility in Japanese children. Diabet Med 34(4):586-589. https://doi.org/10.1111/dme. 13288

33. Albuquerque R, Komsi E, Starskaia I, Ullah U, Lahesmaa R (2021) The role of Interleukin-32 in autoimmunity. Scand J Immunol 93(2):e13012. https://doi.org/10.1111/sji.13012

34. Chen SS, Hu Z, Zhong X-P (2016) Diacylglycerol kinases in T cell tolerance and effector function. Front Cell Dev Biol 4:130. https:// doi.org/10.3389/fcell.2016.00130

35. Zhong X-P, Hainey EA, Olenchock BA et al (2003) Enhanced T cell responses due to diacylglycerol kinase $\zeta$ deficiency. Nat Immunol 4(9):882-890. https://doi.org/10.1038/ni958

36. Kallionpaa H, Elo LL, Laajala E et al (2014) Innate immune activity is detected prior to seroconversion in children with HLA-conferred type 1 diabetes susceptibility. Diabetes 63(7):2402-2414. https:// doi.org/10.2337/db13-1775

37. Ferreira RC, Guo H, Coulson RMR et al (2014) A type I interferon transcriptional signature precedes autoimmunity in children genetically at risk for type 1 diabetes. Diabetes 63(7):2538-2550. https:// doi.org/10.2337/db13-1777

38. Dieguez-Gonzalez R, Calaza M, Perez-Pampin E et al (2008) Association of interferon regulatory factor 5 haplotypes, similar to that found in systemic lupus erythematosus, in a large subgroup of patients with rheumatoid arthritis. Arthritis Rheum 58(5):1264 1274. https://doi.org/10.1002/art.23426

39. Laufer VA, Tiwari HK, Reynolds RJ et al (2019) Genetic influences on susceptibility to rheumatoid arthritis in AfricanAmericans. Hum Mol Genet 28(5):858-874. https://doi.org/10. 1093/hmg/ddy395

40. Graham RR, Kozyrev SV, Baechler EC et al (2006) A common haplotype of interferon regulatory factor 5 (IRF5) regulates splicing and expression and is associated with increased risk of systemic lupus erythematosus. Nat Genet 38(5):550-555. https://doi.org/10. 1038/ng1782

41. Lessard CJ, Sajuthi S, Zhao J et al (2015) Identification of a systemic lupus erythematosus risk locus spanning ATG16L2, FCHSD2, and P2RY2 in Koreans. Arthritis Rheum 68(5):1197-1209. https:// doi.org/10.1002/art.39548

42. Dideberg V, Kristjansdottir G, Milani L et al (2007) An insertion deletion polymorphism in the interferon regulatory factor 5 (IRF5) gene confers risk of inflammatory bowel diseases. Hum Mol Genet 16(24):3008-3016. https://doi.org/10.1093/hmg/ddm259

43. Penninger JM, Sirard C, Mittrücker H-W et al (1997) The interferon regulatory transcription factor IRF-1 controls positive and negative selection of CD8+ Thymocytes. Immunity 7(2):243-254. https:// doi.org/10.1016/S1074-7613(00)80527-0

44. Häcker H, Tseng P-H, Karin M (2011) Expanding TRAF function: TRAF3 as a tri-faced immune regulator. Nat Rev Immunol 11(7): 457-468. https://doi.org/10.1038/nri2998

45. Xie P, Kraus ZJ, Stunz LL, Liu Y, Bishop GA (2011) TNF receptor-associated factor 3 is required for T cell-mediated immunity and TCR/CD28 signaling. J Immunol 186(1):143-155. https:// doi.org/10.4049/jimmunol.1000290

46. Aliahmad P, Kadavallore A, de la Torre B, Kappes D, Kaye J (2011) TOX is required for development of the CD4 T cell lineage gene program. J Immunol 187(11):5931-5940. https://doi.org/10. 4049/jimmunol.1101474

47. Seo H, Chen J, González-Avalos E et al (2019) TOX and TOX2 transcription factors cooperate with NR4A transcription factors to 
impose CD8 + T cell exhaustion. Proc Natl Acad Sci 116(25): 12410-12415. https://doi.org/10.1073/pnas.1905675116

48. Khan O, Giles JR, McDonald S et al (2019) TOX transcriptionally and epigenetically programs CD8 $+\mathrm{T}$ cell exhaustion. Nature 571(7764):211-218. https://doi.org/10.1038/s41586-019-1325-x

49. Wiedeman AE, Muir VS, Rosasco MG et al (2019) Autoreactive CD8+ T cell exhaustion distinguishes subjects with slow type 1 diabetes progression. J Clin Investig 130(1):480-490. https://doi. org/10.1172/JCI126595

50. Diggins KE, Serti E, Muir V et al (2021) Exhausted-like CD8+ T cell phenotypes linked to C-peptide preservation in alefacept- treated T1D subjects. JCI Insight 6(3):e142680. https://doi.org/10. 1172/jci.insight.142680

51. Chiou J, Geusz RJ, Okino M-L et al (2021) Interpreting type 1 diabetes risk with genetics and single-cell epigenomics. Nature 594(7863):398-402. https://doi.org/10.1038/s41586-021-03552-w

Publisher's note Springer Nature remains neutral with regard to jurisdictional claims in published maps and institutional affiliations. 